\title{
The neurobiology of emotion-cognition interactions: fundamental questions and strategies for future research
}

\author{
Hadas Okon-Singer ${ }^{1 * t}$, Talma Hendler ${ }^{2}$, Luiz Pessoa $^{3}$ and Alexander J. Shackman ${ }^{3 * t}$ \\ 'Department of Psychology, University of Haifa, Haifa, Israel \\ 2 Functional Brain Center, Wohl Institute of Advanced Imaging, and School of Psychological Sciences, Faculty of Medicine and Sagol School of Neuroscience, \\ Tel Aviv University, Tel Aviv, Israel \\ ${ }^{3}$ Department of Psychology, Neuroscience and Cognitive Science Program, and Maryland Neuroimaging Center, University of Maryland, College Park, College \\ Park, MD, USA
}

\section{Edited by:}

Leonhard Schilbach, University

Hospital Cologne, Germany

Reviewed by:

Christian Sorg, Klinikum rechts der Isar Technische Universität München, Germany

Elliot Berkman, University of Oregon, USA

\section{${ }^{*}$ Correspondence:}

Hadas Okon-Singer, Department of Psychology, University of Haifa, Mount Carmel, Haifa 3498838, Israel e-mail: hadasos@psy.haifa.ac.il; Alexander J. Shackman, Department of Psychology, Neuroscience and Cognitive Science Program, and Maryland Neuroimaging Center, University of Maryland, 3123 G Biology-Psychology Building, College Park, MD 20742, USA

e-mail: shackman@umd.edu

${ }^{\dagger}$ These authors have contributed equally to this work.
Recent years have witnessed the emergence of powerful new tools for assaying the brain and a remarkable acceleration of research focused on the interplay of emotion and cognition. This work has begun to yield new insights into fundamental questions about the nature of the mind and important clues about the origins of mental illness. In particular, this research demonstrates that stress, anxiety, and other kinds of emotion can profoundly influence key elements of cognition, including selective attention, working memory, and cognitive control. Often, this influence persists beyond the duration of transient emotional challenges, partially reflecting the slower molecular dynamics of catecholamine and hormonal neurochemistry. In turn, circuits involved in attention, executive control, and working memory contribute to the regulation of emotion. The distinction between the 'emotional' and the 'cognitive' brain is fuzzy and context-dependent. Indeed, there is compelling evidence that brain territories and psychological processes commonly associated with cognition, such as the dorsolateral prefrontal cortex and working memory, play a central role in emotion. Furthermore, putatively emotional and cognitive regions influence one another via a complex web of connections in ways that jointly contribute to adaptive and maladaptive behavior. This work demonstrates that emotion and cognition are deeply interwoven in the fabric of the brain, suggesting that widely held beliefs about the key constituents of 'the emotional brain' and 'the cognitive brain' are fundamentally flawed. We conclude by outlining several strategies for enhancing future research. Developing a deeper understanding of the emotional-cognitive brain is important, not just for understanding the mind but also for elucidating the root causes of its disorders.

Keywords: ACC, amygdala, anxiety, depression, emotion control and regulation, EEG/ERP, fMRI, PFC
Until the 20th century, the study of emotion and cognition was largely a philosophical matter. Although modern perspectives on the mind and its disorders remain heavily influenced by the introspective measures that defined this earlier era of scholarship, the last several decades have witnessed the emergence of powerful new tools for assaying the brain and a remarkable acceleration of research to elucidate the interplay of emotion and cognition (Pessoa, 2013; Braver et al., 2014; Dolcos and Denkova, 2014). The immediate goal of our Special Research Topic was to survey recent advances in understanding how emotional and cognitive processes interact, how they are integrated in the brain, and the implications for understanding the mind and its disorders (OkonSinger et al., 2014b; Figure 1). Here, we consider ways in which this rapidly growing body of work begins to address some more fundamental questions about the nature of cognition-emotion interactions, highlighting key points of consensus. By focusing attention on the most important outstanding questions, we hope to move the field forward. First, we hope that answers provided by our contributors will stimulate discussion. Second, we hope that juxtaposing clear theoretical goals against the current state of the science will motivate new and impactful research. Clearly, our understanding of emotion-cognition interactions remains far from complete. Indeed, we are reminded of Ekman and Davidson's comment: "There are many promising findings, many more leads, [and] a variety of theoretical stances" (Ekman and Davidson, 1994, p. 3). We conclude by outlining several strategies for enhancing future research. With continuing effort, some of the fundamental questions will be decisively addressed. In some cases, the questions themselves will evolve, as in other areas of the biological sciences.

\section{HOW DOES EMOTION INFLUENCE COGNITION?}

Many of our contributors highlighted evidence that the perception of emotionally-salient stimuli and the experience of emotional states can profoundly alter cognition.

\section{EMOTIONAL CUES GRAB EXOGENOUS ATTENTION AND MODULATE ENDOGENOUS ATTENTION}

There is abundant evidence that emotionally-salient cuessnakes, spiders, and angry faces-strongly influence attention 


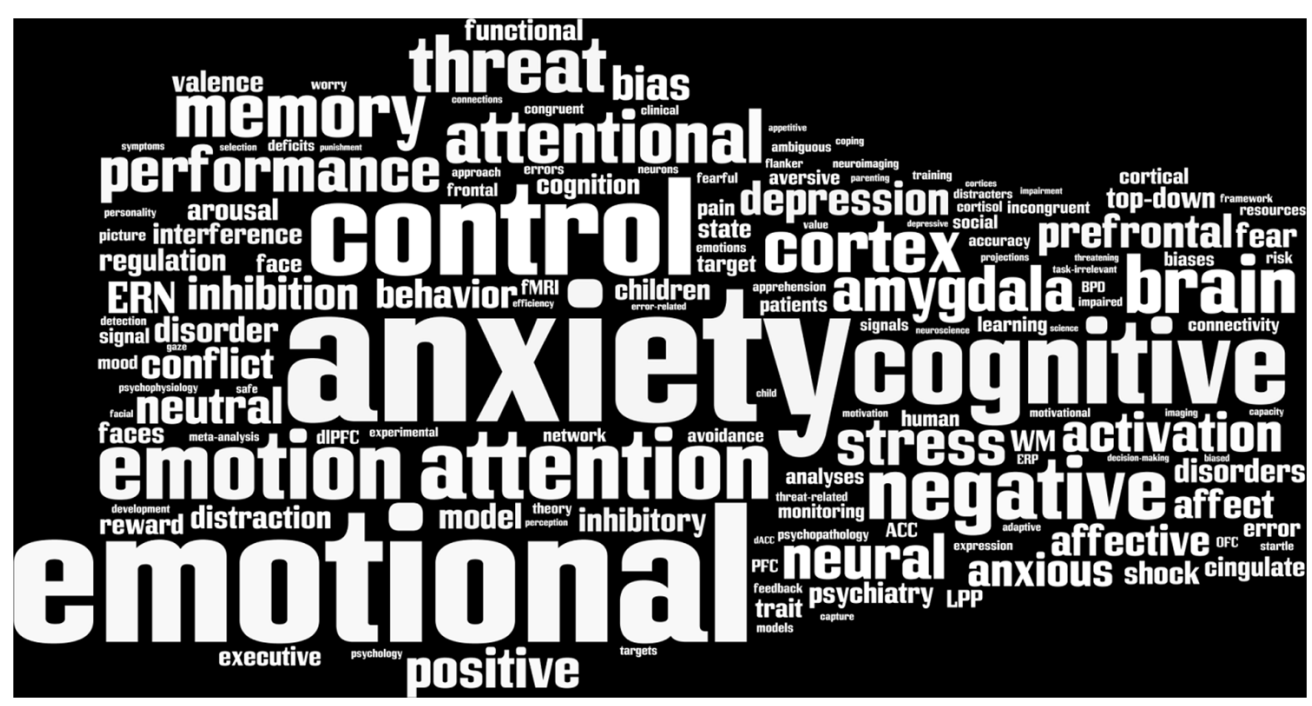

FIGURE 1 |The top 200 scientific terms used in the Special Research Topic. The typeface is scaled proportional to the frequency of each term. The figure was generated using http://www.wordle.net.

(e.g., Siman-Tov etal., 2009; Lerner etal., 2012; Pourtois etal., 2013; Carretié, 2014) the ability to selectively respond to relevant aspects of the environment while inhibiting potential sources of distraction and competing courses of action (Desimone and Duncan, 1995; Miller and Cohen, 2001). The focus of attention is determined by the pervasive competition between exogenous (often termed 'stimulusdriven' or 'bottom-up') and endogenous (often termed 'goaldirected' or 'top-down' attention) mechanisms (Egeth and Yantis, 1997).

With respect to exogenous attention, a number of contributors describe new evidence that emotionally-charged cues are more attention-grabbing than neutral cues and highlight recent efforts to specify the mechanisms underlying this bias (Holtmann et al., 2013; McHugo et al., 2013; Peers etal., 2013; Stollstorff etal., 2013). Along the way, McHugo et al. (2013) provide a useful tutorial on methods for quantifying the capture of attention by emotional cues (e.g., dot-probe, emotional attentional blink).

Importantly, attention can also be guided in an endogenous fashion by internal goals (e.g., rules, instructions, and plans) as well as moods and motivational states (e.g., feeling anxious or hungry). Mohanty and Sussman (2013) discuss evidence demonstrating that emotion and motivation can guide attention to congruent cues (e.g., food when hungry). In particular, they show that subcortical regions proximally involved in determining value and orchestrating emotional states (e.g., amygdala, substantia nigra) can facilitate endogenous attentional processes implemented in frontoparietal regions and can strengthen activation in relevant sensory regions (e.g., face-selective regions of the fusiform gyrus when anticipating an angry face). This extended network, encompassing sensory, attentional, and emotional circuits, facilitates the rapid detection of emotionally-significant information.

\section{ATTENTIONAL BIASES TO EMOTIONAL CUES ARE PLASTIC}

Anxious individuals tend to allocate excess attention to threat and there is evidence that this cognitive bias causally contributes to the development and maintenance of anxiety disorders (Bar-Haim et al., 2007; Hakamata et al., 2010; MacLeod and Mathews, 2012; Singer et al., 2012; Van Bockstaele et al., 2013; MacLeod and Clarke, 2015). Extreme anxiety and behavioral inhibition often emerges early in development (Fox et al., 2005a; Blackford and Pine, 2012; Fox and Kalin, 2014), raising important questions about the degree to which childhood attentional biases to threat are plastic and can be influenced by early experience (Shechner et al., 2012; BarHaim and Pine, 2013; Henderson et al., 2014; MacLeod and Clarke, 2015).

Here, Kessel et al. (2013) provide tantalizing correlative evidence that emotional biases in attention are influenced by caregiver style. Using an innovative combination of behavioral and electrophysiological techniques, they show that although temperamentally inhibited children allocate more attention to aversive cues, this is reduced among the offspring of parents who rely on encouragement, affection, and appreciation to reinforce positive behavior. A key challenge for future research will be to test whether targeted interventions aimed at cultivating more salubrious parenting styles have similar consequences. Prospective designs (e.g., before and after exposure to a negative life event or trauma) would provide another powerful approach for understanding the plasticity of emotional attention (Admon etal., 2009, 2012).

\section{EMOTION EXERTS PERSISTENT EFFECTS ON ATTENTION}

Emotions are often conceptualized as fleeting and most imaging and psychophysiological studies of emotion focus on transient responses to punctate emotional challenges. Yet, there is growing evidence that emotions can have lingering consequences for 
cognition and behavior (Davidson, 2004; Suls and Martin, 2005; Hajcak and Olvet, 2008; Qin et al., 2009).

Here, for example, Vaisvaser et al. (2013) combined serial measures of emotional state, neuroendocrine activity, and restingstate brain activity to demonstrate that alterations in amygdalahippocampal functional connectivity persist for more than $2 \mathrm{~h}$ following exposure to intense social stress. Along conceptually similar lines, Morriss et al. (2013) use electrophysiological techniques to show that endogenous attention is potentiated for several seconds following brief emotional challenges (i.e., standardized emotional images).

Several threads of evidence highlight the importance of understanding the mechanisms that govern variation in the speed of recovery from emotional perturbation. In particular, individual differences in emotional recovery (a) strongly predict personality traits, such as neuroticism, that confer increased risk of developing psychopathology (e.g., Blackford et al., 2009; Schuyler etal., 2014); and (b) are sensitive to adversity and chronic stress exposure, two other well-established risk factors (Lapate et al., 2014). An important challenge for future research will be to identify the neural circuitry and molecular pathways that support the enduring effects of emotion on endogenous attention and to clarify the intermediate processes that link variation in emotional recovery to mental health and disease.

\section{DISTRACTING EMOTIONAL CUES READILY PENETRATE THE GATE PROTECTING WORKING MEMORY}

Endogenous attention is tightly linked with working memory (Postle, 2006; D'Esposito and Postle, 2014; Sreenivasan et al., 2014). The transient representation of task-sets, goals, and other kinds of information in working memory plays a crucial role in sustaining goal-directed attention and guiding behavior in the face of potential distraction (Miller and Cohen, 2001). In short, information held in working memory is a key determinant of our momentary thoughts, feelings, and behavior. Importantly, the capacity of working memory is strongly determined by the ability to filter or gate irrelevant information (Vogel et al., 2005; McNab and Klingberg, 2007; Awh and Vogel, 2008).

Here, Stout et al. (2013) used a well-established electrophysiological marker of working memory storage (i.e., contralateral delay activity; Vogel and Machizawa, 2004) to show that threatrelated distractors (i.e., task-irrelevant fearful faces) are stored in working memory and that this filtering inefficiency is exaggerated in dispositionally-anxious individuals. Once in working memory, emotional information is poised to hijack endogenous attention and other kinds of top-down control mechanisms. From a psychiatric perspective, this emotional gating deficit may help to explain the persistence of heightened negative affect (e.g., anxiety, sadness) among patients with emotional disorders (Grupe and Nitschke, 2013; Cohen et al., 2014; Stout et al., 2014). An important challenge for future studies will be to use hemodynamic imaging techniques, such as fMRI, to clarify the neural circuitry underlying emotional gating deficits. A variety of evidence suggests that the pulvinar may play an important role (Pessoa and Adolphs, 2010; Arend et al., 2014).

\section{DISTRACTING EMOTIONAL CUES DISRUPT COGNITIVE CONTROL AND WORKING MEMORY}

Classically, cognition and emotion have been viewed as oppositional forces (Damasio, 2005a; Okon-Singer et al., 2007, 2011; Shackman et al., in press). From this perspective, moods and other kinds of emotional states are responsible for short-circuiting cognition.

Consistent with this view, Kalanthroff et al. (2013) show that emotional distractors disrupt cognitive control. Cognitive control encompasses the range of processes (e.g., endogenous attention, inhibition, and learning) that are engaged when habitual responses are not sufficient to sustain goal-directed behavior, as in stopsignal, go/no-go, Stroop, and Eriksen flanker tasks (Shackman et al., 2011b). Here, the authors demonstrate that the brief presentation of emotional images disrupts performance in the stop-signal task, a widely used index of inhibitory control (see also Pessoa et al., 2012).

Likewise, Iordan et al. (2013) review evidence that emotional distractors disrupt working memory. Converging with other work focused on emotion-related distraction (Bishop, 2007; Etkin, 2012; Bishop and Forster, 2013; Etkin et al., 2013; Okon-Singer et al., 2014a; van Ast et al., 2014), they suggest that degraded performance reflects two processes: (a) increased engagement of regions involved in processing socio-emotional information and orchestrating emotional expressions (e.g., amygdala), and (b) a reduction of delay-spanning activity in frontoparietal cortex.

\section{EMOTION STRENGTHENS SOME COGNITIVE PROCESSES WHILE WEAKENING OTHERS}

With the ascent of evolutionary theory in the 19th century (Darwin, 1872/2009, 1872), many scientists adopted the view that emotions are functional and enhance fitness (Susskind et al., 2008; Todd et al., 2012; Sandi, 2013; Schwabe and Wolf, 2013; Todd and Anderson, 2013); in short, that emotions are more adaptive than not and "that there is typically more cooperation than strife" between emotion and cognition (Levenson, 1994).

Consistent with this more nuanced perspective, the contributions from Clarke and Johnstone (2013), Morriss et al. (2013), Robinson etal. (2013a, 2013b), Vytal et al. (2013) provide evidence that experimentally-elicited anxiety facilitates some kinds of information processing, while degrading others. In particular, they provide considerable evidence that anxiety: (a) enhances vigilance, potentiating early sensory cortical responses to innocuous environmental stimuli, increasing the likelihood that emotionally salient information will be detected; and (b) disrupts working memory.

The molecular basis of emotion's deleterious impact on working memory is reviewed by Shansky and Lipps (2013). Building on pioneering work by Arnsten and Goldman-Rakic (1998) and Arnsten (2009), the authors describe evidence that stress strongly influences catecholamine (i.e., dopamine and norepinephrine) and glucocorticoid levels in the prefrontal cortex (PFC) in ways that degrade delay-spanning neuronal activity.

Shansky and Lipps (2013) also describe important new evidence that sex hormones, such as estrogen, can exacerbate the impact of stress on prefrontal function. Along these lines, Sacher 
etal. (2013) review human imaging studies showing that the structure and function of brain circuits involved in emotion generation and regulation are strongly and dynamically modulated by cyclic fluctuations in sex hormones (see also Sacher et al., 2012). Taken together, these observations underscore the plasticity of emotion-cognition interactions and provide promising clues about the origins of well-established sex differences in the prevalence of stress-related disorders, such as anxiety and depression (Kessler et al., 2012; Kendler and Gardner, 2014).

\section{EMOTIONAL STATES PROMOTE MOOD-CONGRUENT THOUGHTS AND ACTIONS}

Moods and other, more transient emotional states tend to encourage congruent thoughts and actions (e.g., Lerner et al., 2015), a process that is necessarily mediated by enduring changes in brain activity and connectivity (cf. Vaisvaser et al., 2013). Here, Van Dessel and Vogt (2012) demonstrate that mood increases the amount of attention allocated to moodcongruent cues. Schick et al. (2013) provide evidence that individuals at risk for developing depression interpret motivationally ambiguous cues in a less positive light. Harlé etal. (2013) describe a novel Bayesian computational framework for understanding the mechanisms underlying mood-congruency effects. An important advantage of this framework is that it generates explicit mechanistic hypotheses. For example, the model predicts that anxiety facilitates behavioral avoidance because it leads to inflated expectations about the need for avoidant behavior and increased expectations of punishment or error. Furthermore, fitting model parameters to observable behavior affords an opportunity to identify the underlying determinants of mood-congruency effects in healthy and clinical populations.

\section{EMOTIONAL TRAITS INFLUENCE COGNITIVE PERFORMANCE, EVEN WHEN EMOTIONAL CUES, AND CHALLENGES ARE ABSENT}

Emotional traits are often conceptualized as diatheses for emotional states (Matthews et al., 2009). Thus, individuals with high levels of neuroticism or negative emotionality are thought to be prone to exaggerated anxiety in the face of trait-relevant cues, contexts, and challenges (e.g., punishment, negative feedback), as illustrated in the contributions from Kessel et al. (2013), Moser et al. (2013), and Proudfit et al. (2013). Yet, a considerable body of neurophysiological evidence indicates that emotional traits are embodied in the on-going activity and connectivity of the brain (Canli et al., 2005; Fox et al., 2008; Shackman et al., 2009; Rohr etal., 2013; Birn etal., 2014a,b). Likewise, the sustained levels of heightened vigilance and distress characteristic of individuals with anxiety disorders are most apparent in the absence of clear and imminent threat (Davis et al., 2010; Lissek, 2012; Grupe and Nitschke, 2013). These observations raise the possibility that emotional traits could influence cognition in the absence of explicit emotional distraction or challenge (Watson and Clark, 1984; Bolger and Schilling, 1991; Suls and Martin, 2005).

Here, Berggren et al. (2013) provide compelling evidence that trait anxiety is associated with degraded cognitive control, indexed using an anti-saccade task under load. This new observation adds to a growing literature showing that "hot" emotional traits can influence "cold" cognition (Shackman et al., 2006; Eysenck et al., 2007; Bishop, 2009; Berggren and Derakshan, 2013, 2014; Cavanagh and Shackman, 2014), a point that we develop more fully in the subsequent section focused on the integration of emotion and cognition.

\section{HOW DOES EMOTION INFLUENCE EMOTION?}

An important but rarely addressed question in psychology and psychiatry concerns the potential influence of emotions on one another and concomitant motivational states. For example, are we less likely to experience excitement or joy on a day where we're feeling frazzled, depressed, or worn out (Arnsten, 1998, 2009; Pizzagalli, 2014)?

\section{EMOTION ALTERS REINFORCER SENSITIVITY}

Building on earlier work by Bogdan and Pizzagalli (2006), Pizzagalli et al. (2007), Bogdan et al. (2010), and Berghorst et al. (2013) demonstrate that experimentally-elicited anxiety selectively reduces sensitivity to reward, suggesting a mechanism that may contribute to the high rate of comorbidity between anxiety and anhedonia (Southwick et al., 2005). Notably, this effect was only observed in the subset of subjects who were most responsive to the anxiety induction (i.e., threat of noxious electric shock). Given evidence that many individuals will never experience a mood or anxiety disorder (Kessler et al., 2012), this paradigm may provide a means of identifying those at greatest risk. Methodologically, this observation underscores the necessity of including independent measures of emotion in studies of emotion-cognition interactions (Shackman et al., 2006).

\section{HOW DOES COGNITION INFLUENCE AND REGULATE EMOTION?}

Humans frequently regulate their emotions and they do so using a variety of implicit and explicit cognitive strategies (Gross, 1998a,b; Gross and Thompson, 2007; Gross et al., 2011; Webb et al., 2012; Okon-Singer et al., 2013). Implicit strategies are unintentional and appear to occur without effort or insight. In contrast, explicit strategies are voluntary and demand a degree of effortful control.

Several contributors to our Special Research Topic described new insights into the mechanisms supporting the cognitive regulation of emotion and the role of emotion regulation in psychiatric disorders, such as depression.

\section{ATTENTION REGULATES EMOTION}

Perhaps the most basic strategy for reducing distress is attentional avoidance; that is, to simply look away from the source of distress (Xing and Isaacowitz, 2006). Overt attentional redeployment is a potent means of regulating the engagement of subcortical structures, such as the amygdala, that play a key role in orchestrating emotional states (Pessoa et al., 2002; Dalton et al., 2005; Dalton et al., 2007; van Reekum etal., 2007; Urry, 2010; Okon-Singer et al., 2014a).

Here, Aue etal. (2013b) employed an innovative combination of eyetracking, psychophysiology, and fMRI to explore visual avoidance in spider phobics. Taking an individual differences approach, they demonstrate that enhanced activation in 
the amygdala and dorsal striatum to spider images was predictive of increased visual avoidance among arachnophobes. Peripheral measures of autonomic arousal showed a similar pattern, suggesting that arachnophobes endogenously redirect attention as a means of regulating their extreme fear, a strategy that might be non-adaptive in the long term (Grupe and Nitschke, 2013). A key challenge for future research will be to clarify the order of these effects (i.e., fear $\rightarrow$ attention avoidance $\rightarrow$ reduced fear), perhaps by leveraging the millisecond temporal resolution afforded by facial electromyography (e.g., Lee et al., 2009; Heller et al., 2014). Elucidating the mechanisms supporting the recursive interplay of emotion and attention and the mutual influences of different processing biases (Aue et al., 2013a) would inform our understanding of disorders, like post-traumatic stress, that are characterized by dysregulated emotion and aberrant attention to emotionallysalient cues (e.g., Admon et al., 2013; Wald et al., 2013) and set the stage for developing improved interventions (MacLeod and Mathews, 2012; Bar-Haim and Pine, 2013; MacLeod and Clarke, 2015).

\section{THE CHOICE OF COGNITIVE REGULATION STRATEGY DEPENDS ON THE SITUATION}

Sheppes and Levin (2013) emphasize that humans frequently use effortful cognitive strategies to cope with and regulate their emotions (e.g., Egloff et al., 2006; Ehring et al., 2010). For example, they may try to distract themselves or they may try to reappraise the situation in a more positive light. Sheppes and Levin (2013) provide evidence that not only do individuals have the capacity to flexibly choose emotion regulation strategies, but that they do so in ways that are strongly influenced by the emotional context (e.g., choosing to reappraise when presented with mild negative pictures, and to distract themselves in face of highly aversive stimulation).

\section{WORKING MEMORY REGULATES EMOTION}

Some strategies for regulating emotional distress, such as reappraisal, require the effortful maintenance of an explicit regulatory goal. Rolls (2013) reviews evidence suggesting that this critically depends on working memory. More broadly, he suggests that goals, attentional sets, and other kinds of declarative knowledge held in working memory play a central role in regulating the output of emotional systems.

\section{HOW ARE EMOTION AND COGNITION INTEGRATED?}

Humans tend to experience cognition and emotion as fundamentally different. Emotion is infused with feelings of pleasure or pain and manifests in readily discerned changes in the body, whereas cognition often appears devoid of substantial hedonic, motivational, or somatic features. These apparent differences in phenomenological experience and peripheral physiology led many classical scholars to treat emotion and cognition as distinct mental faculties (de Sousa, 2014; Schmitter, 2014). But contemporary theorists have increasingly rejected the claim that emotion and cognition are categorically different (Damasio, 2005b; Duncan and Barrett, 2007; Lindquist and Barrett, 2012; Barrett and Satpute, 2013; Pessoa, 2013), motivated in part by recent imaging evidence demonstrating the overlap of emotional and cognitive processes in the brain (e.g., Shackman et al., 2011b; Raz etal., 2012, 2014). The neural integration of emotion and cognition should not be surprising-after all, the human brain did not evolve to optimize performance on laboratory measures of 'cold' cognition or to passively respond to experimental manipulations of emotion, such as threat of shock. Our brain, like that of other animals, is the product of evolutionary pressures that demanded neural systems capable of using information about pleasure and pain, derived from stimuli saturated with hedonic and motivational significance, to adaptively regulate attention, learning, somatic arousal, and action.

A number of contributors highlighted advances in our understanding of the neural mechanisms that serve to integrate emotion and cognition.

\section{CANONICAL TERRITORIES OF THE 'COGNITIVE' BRAIN REGULATE EMOTION}

The dorsolateral prefrontal cortex (dlPFC) is a canonically 'cognitive' region of the brain, well known for its critical role in reasoning and higher cognition (e.g., endogenous attention, working memory, and cognitive control; Roberts et al., 1998; Miller and Cohen, 2001; D'Esposito and Postle, 2014). Yet, there is growing evidence that the dlPFC plays a key role in the top-down control of emotion and motivated behavior (Fox et al., 2005b; Koenigs et al., 2008; Zaretsky et al., 2010; Buhle et al., 2013; Frank et al., 2014; Treadway et al., 2014).

Here, Clarke and Johnstone (2013) and Iordan et al. (2013) provide tantalizing, albeit correlational, evidence that dlPFC acts to protect the contents of working memory from emotional distraction. This converges with work by Peers et al. (2013) and Stollstorff et al. (2013) indicating that dlPFC plays a key role in regulating the focus of attention in the face of potentially distracting emotional cues.

Rolls (2013) extends this perspective to decision-making, arguing that behavior reflects a pervasive, dynamic competition between two kinds of brain systems: (a) emotional systems, including circuits centered on the amygdala and ventral striatum, that have been genetically programmed by our phylogenetic history (e.g., fear elicited by danger, joy elicited by sweets and fat); and (b) cognitive systems, such as the frontoparietal network, that are informed by our ontogenetic history and governed by our declarative knowledge and explicit goals (i.e., pick the healthy orange, not the unhealthy candy bar; cf. Hare et al., 2008, 2009). Rolls emphasizes that the lateral PFC can override the output of emotion circuitry, biasing behavior in favor of our explicit goals. John et al. (2013) articulate a complementary perspective, reviewing evidence that the PFC and amygdala functionally interact via a complex anatomical network of recurrent cortical and thalamic projections and intra-amygdalar microcircuits (see also Pessoa and Adolphs, 2010; Pessoa, 2012; Pessoa et al., 2012; Birn et al., 2014a,b; Treadway et al., 2014).

Evidence linking the dlPFC to mood and anxiety disorders, as in the papers contributed by Crocker et al. (2013) and Warren et al. (2013), underscores the importance of developing a more sophisticated understanding of the role played by 'cognitive' regions in normal and disordered emotion. 


\section{CANONICAL TERRITORIES OF THE 'COGNITIVE' BRAIN ARE REGULATED BY EMOTION}

Regulation is a two-way street. Just as 'cognitive' systems (e.g., dlPFC) regulate emotion, 'emotion' systems (e.g., amygdala) are well positioned to regulate 'cognitive' systems via their influence over the brainstem neurotransmitter systems that govern the quality of information processing (e.g., neuronal signal-tonoise) in cortical regions, as highlighted in the review contributed by Shansky and Lipps (2013). Via these mechanisms, the amygdala is endowed with the capacity to transiently assume enhanced control over attention and behavior in situations that favor immediate responses over slower, more deliberate reasoning (Davis and Whalen, 2001; Arnsten, 2009).

\section{ADAPTIVE AND MALADAPTIVE BEHAVIOR REFLECTS THE INTEGRATED CONTRIBUTIONS OF EMOTION AND COGNITIVE CONTROL}

Oftentimes, cognitive control is associated with laboratory tasks that require the detection and adjudication of response conflict, as with incongruent trials of the Stroop, Eriksen Flanker, and go/no-go tasks. Yet, it is clear that control processes are engaged by a much broader range of cognitive and emotional challenges (e.g., Pochon etal., 2008; Shenhav etal., 2013). In particular, control is engaged when there is uncertainty about the optimal course of action (e.g., probabilistic learning), when potential actions are associated with the possibility of error or punishment, or when there is competition between alternative courses of action (e.g., flee/freeze, go/no-go). These features are hallmarks of dangerous environments, both in the real world and in laboratory studies of fear, anxiety, and pain. Consequently, it has long been thought that control processes are engaged in threatening environments in order to monitor risk, optimize learning, and avoid potentially catastrophic actions (Norman and Shallice, 1986; Gray and McNaughton, 2000). These theoretical considerations raise the possibility that the neural circuitry underlying 'cognitive' control also contributes to the negative emotions elicited by potential threat. Indeed, there is compelling evidence from functional imaging studies that negative affect and cognitive control paradigms consistently activate an overlapping region of the midcingulate cortex (MCC; Shackman et al., 2011b; Lin et al., 2014). This overlap is consistent with anatomical evidence suggesting that the MCC represents a hub where information about pain, threat, and other more abstract forms of potential punishment and negative feedback are synthesized into a biasing signal that modulates regions involved in expressing fear and anxiety, executing goal-directed behaviors, and biasing the focus of selective attention (Shackman etal., 2011b; Cavanagh and Shackman, 2014). Taken together, these observations suggest that anxiety and other emotions are tightly integrated with control processes implemented in the MCC and other brain regions.

Along these lines, Morrison et al. (2013) show that even simple, phylogenetically-ancient kinds of motivated behavior, such as the reflexive withdrawal from pain or the learned avoidance of pain-related contexts, are dynamically shaped by complex, hierarchically-organized networks of feedforward and feedback connections that serve to integrate 'emotional' (e.g., value, risk) and 'cognitive' computations (e.g., prediction error, attention allocation, action selection) in ways that support adaptive behavior (for convergent perspectives, see the contributions from Rolls, 2013, and John et al., 2013).

Dreisbach and Fischer (2012) describe other evidence consistent with this integrative perspective. In particular, they show that 'cognitive' conflict is aversive. This converges with a growing body of evidence demonstrating that conflict and other prompts for increased control (e.g., errors, punishment), are experienced as unpleasant and facilitate avoidance (Botvinick, 2007; Kool et al., 2010; Dreisbach and Fischer, 2012; Schouppe et al., 2012; Lindström etal., 2013; Proudfit et al., 2013; Shenhav and Buckner, 2014).

If negative emotions are indeed integrated with control processes, we would expect that anxiety and control should covary. That is, one would expect a degree of functional convergence between measures of anxiety and control-related activity in the MCC or other regions (i.e., convergent validity; Campbell and Fiske, 1959). Consistent with this possibility, Moser et al. (2013) provide compelling meta-analytic evidence that error-related signals generated in the MCC are enhanced among anxiety patients and individuals with heightened negative emotionality. This indicates that negative emotionality, a fundamental dimension of childhood temperament and adult personality (Caspi et al., 2005), involves systematic differences in the way that the brain responds to prompts for cognitive control.

McDermott etal. (2013) describe important new evidence, gleaned from the study of Romanian orphans, that MCC control signals are plastic. In particular, they demonstrate that MCC-generated control signals are profoundly shaped by early experience in ways that confer risk or resilience for later socioemotional problems. This underscores the need to clarify the neurodevelopmental mechanisms that serve to integrate emotion and cognition in the laboratory and in daily life.

\section{UNDERSTANDING THE INTERPLAY OF EMOTION AND COGNITION: STRATEGIES FOR FUTURE RESEARCH}

Despite substantial progress, a number of important questions about the interaction of emotion and cognition remain unanswered. In this final section, we highlight three strategies for enhancing research in the cognitive-affective sciences (for more general recommendations about best research practices, see Button et al., 2013a,b,c; David et al., 2013; Chalmers et al., 2014; Ioannidis et al., 2014a,b).

\section{UNDERSTANDING THE SIGNIFICANCE OF EMOTIONAL-COGNITION INTERACTIONS IN THE LABORATORY REQUIRES MORE SOPHISTICATED MEASURES OF BEHAVIOR IN THE REAL WORLD}

Most investigations of emotion, cognition, and their interplay rely on a small number of well-controlled, but highly artificial paradigms for manipulating emotion and cognition (e.g., static aversive images and threat of shock to elicit anxiety; Coan and Allen, 2007). Although these methods have afforded a number of critical insights, their real-world significance remains poorly understood. For example, are attentional biases to threat, as indexed by the dot-probe or other laboratory assays, predictive of elevated behavioral inhibition or distress in daily life? Is amygdala activation to fearful faces predictive of heightened social reticence 
or risk avoidance outside the scanner (see Admon et al., 2009 for preliminary affirmative evidence)? Does the eliciting stimulus (e.g., faces or aversive images) matter? Are measures of functional connectivity or network-based metrics (e.g., node centrality; cf. McMenamin et al., 2014) more predictive than regional activation of behavior in the real world?

Given the limitations of ambulatory measures of brain activity - there is no 'fMRI helmet' as yet-addressing these fundamental questions requires pairing assays of brain and behavior obtained in the laboratory with measures of thoughts, feelings, and behavior obtained in the field. Recent work combining fMRI with ecological momentary assessment (EMA) techniques, in which surveys are repeatedly delivered to participants' mobile devices, highlights the value of this approach for identifying the neural systems underlying naturalistic variation in mood and behavior, a central goal of psychology, psychiatry, and the behavioral neurosciences (Forbes et al., 2009; Berkman and Falk, 2013; Lopez et al., 2014; Wilson et al., 2014). The widespread dissemination of smart phone technology affords additional, largely unrealized opportunities for objectively and unobtrusively quantifying daily behavior (e.g., assessments of activity and context based on accelerometer and geographical positioning system data (Gosling and Mason, 2015). In short, combining EMA with laboratory assays provides a critical means of testing theoretical validity and clinical relevance (e.g., does activation of the ventral striatum support craving and approach?), a novel strategy for assessing and dissociating the functional significance of new assays and derivative measures (e.g., functional connectivity between the striatum and PFC), and an impetus for the development of laboratory probes that more closely resemble the challenges we routinely encounter in life (e.g., appetitive social cues and temptations).

\section{UNDERSTANDING THE INTERPLAY OF EMOTION AND COGNITION REQUIRES A DYNAMIC NETWORK PERSPECTIVE}

Emotion and cognition emerge from the dynamic interactions of large-scale brain networks. Put simply, fear, joy, attention, working memory, and other psychological constructs cannot be mapped to isolated brain regions because no one region is both necessary and sufficient. Likewise, similar profiles of impairment can emerge from damage to different regions located within in the same functional network (Karnath and Smith, 2014; Oler et al., in press). This is not a new or contentious idea; pioneers like Mesulam, GoldmanRakic, and LeDoux highlighted the importance of distributed neural circuits more than two decades ago and there is widespread agreement amongst basic and translational researchers (GoldmanRakic, 1988; LeDoux, 1995; Mesulam, 1998; Bullmore and Sporns, 2012; LeDoux, 2012; Uhlhaas and Singer, 2012; Anticevic et al., 2013).

Thus, understanding the interplay of emotion and cognition requires that we accelerate the transition from localization strategies (i.e., mapping isolated brain structures to function; sometimes termed 'neo-phrenology') to a network-centered approach. This will require harnessing the kinds of analytic tools (e.g., functional connectivity fingerprinting, graph-theoretic and machine-learning approaches) that are necessary for elucidating how adaptive and maladaptive behavior emerges from functional coalitions of brain regions (Kinnison et al., 2012; Raz et al., 2012, 2014; Anticevic et al., 2013; McMenamin et al., 2014; Uddin etal., 2014). A key challenge for future research will be to harness new techniques (e.g., EEG/fMRI fusions, sliding window analyses of functional connectivity, EEG source models of connectivity) for understanding how network activity dynamically changes across the broad range of time scales on which emotion and cognition interact (Pessoa and Adolphs, 2010; Shackman et al., 2011a; Johnson et al., 2012; Raz et al., 2012, 2014).

Computationally explicit strategies (i.e., where quantitative parameters of an abstract computational model are fit to behavioral or physiological measures), already common in the neuroeconomics literature, and information-based approaches, such as multivoxel pattern analysis (MVPA), that are increasingly common in the cognitive neuroscience literature, provide powerful tools for discovering the functional significance of regions and networks associated with emotional and cognitive perturbations and disorders (e.g., Hartley and Phelps, 2012; Montague et al., 2012; Lewis-Peacock and Norman, 2013). For example, traditional univariate fMRI analyses use regression to predict the activity of voxels, one-by-one, given some mental state (e.g., experiencing pain). While this strategy has proven enormously generative, it does not provide strong evidence as to whether overlapping patterns of fMRI activation (e.g., during physical and social pain; Wager et al., 2013; Woo et al., 2014) reflect the same mental representation. MVPA provides a means of addressing this problem. MVPA classifies mental states given a pattern of activity across voxels; in effect, treating each voxel as a weighted source of information about mental state. This contributes to the identification of the combinatorial code (i.e., pattern of activity across voxels) instantiating a particular mental state (e.g., experiencing anxiety) and to test whether that neural signature is reinstated at other times (e.g., performing a cognitive control task), an essential step in elucidating the functional contributions of territories that are commonly recruited by cognitive and emotional challenges (e.g., dlPFC, MCC, anterior insula).

Embracing a network perspective also reminds us that the functional circuitry underlying the interplay of emotion and cognition is likely to be complex and need not recapitulate the simpler pattern of direct projections revealed by invasive anatomical tracing techniques [cf. the contributions from John et al. (2013), Morrison et al. (2013), and Rolls (2013)]. Indeed, there is ample evidence of robust functional connectivity between brain regions that lack direct structural connections and increasing evidence that regulatory signals can rapidly propagate across complex, indirect pathways in ways that enable emotion (e.g., motivational salience or value) to be integrated with perception and other kinds of on-going information processing (Vincent et al., 2007; Ekstrom et al., 2008; Honey et al., 2009; Pessoa and Adolphs, 2010; Adachi et al., 2012; Birn et al., 2014a). Deciphering the functional significance of this 'connectomic' complexity is likely to require more advanced analytic approaches, such as probabilistic machinelearning techniques (Murphy, 2012). The combination of ongoing advances in computational methods as well as developments in brain imaging acquisition techniques (e.g., those supported by 
the U.S. BRAIN initiative) will undoubtedly contribute to these efforts.

\section{UNDERSTANDING THE INTERPLAY OF EMOTION AND COGNITION REQUIRES MECHANISTIC RESEARCH}

Most of the contributors to the Special Research Topic used noninvasive techniques, such as fMRI, to trace associations between emotion and cognition, on the one hand, and brain function on the other. Aside from unresolved questions about the origins and significance of the measured signals (e.g., Logothetis, 2008), the most important limitation of these techniques is that they do not address causation. A crucial challenge for future studies is to develop a mechanistic understanding of the distributed networks that support the interplay of emotion and cognition. This can be achieved by combining mechanistic techniques (e.g., optogenetics) or invasive analyses of neuromolecular pathways in animal models with the same whole-brain imaging strategies routinely applied in humans (Borsook et al., 2006; Lerman et al., 2007; Fox et al., 2010, 2012; Lee etal., 2010; Desai et al., 2011; Casey et al., 2013; Narayanan et al., 2013; Roseboom et al., 2014). Similar strategies can be used with patients with circumscribed brain damage (e.g., Nomura etal., 2010; Gratton et al., 2012; Motzkin et al., 2014). Combining fMRI or EEG with non-invasive perturbation techniques (e.g., transcranial magnetic stimulation or transcranial direct current stimulation) or pharmacological manipulations provides another opportunity for understanding how regional changes in brain activity alter network function and, ultimately, behavior (Paulus et al., 2005; Guller et al., 2012; Chen et al., 2013; Reinhart and Woodman, 2014). Prospective longitudinal designs represent another fruitful approach to identifying candidate mechanisms, especially in relation to the development of neuropsychiatric disorders (Admon et al., 2013).

\section{CONCLUSION}

The last decade has witnessed an explosion of interest in the interplay of emotion and cognition. The research embodied in this Special Research Topic highlights the tremendous advances that have already been made. In particular, this work demonstrates that emotional cues, emotional states, and emotional traits can strongly influence key elements of on-going information processing, including selective attention, working memory, and cognitive control. Often, this influence persists beyond the duration of transient emotional challenges, perhaps reflecting slower changes in neurochemistry. In turn, circuits involved in attention and working memory contribute to the voluntary regulation of emotion. The distinction between the 'emotional' and the 'cognitive' brain is blurry and context-dependent. Indeed, there is compelling evidence that territories (e.g., dlPFC, MCC) and processes (e.g., working memory, cognitive control) conventionally associated with cognition play a central role in emotion. Furthermore, putatively emotional and cognitive regions dynamically influence one another via a complex web of recurrent, often indirect anatomical connections in ways that jointly contribute to adaptive behavior. Collectively, these observations show that emotion and cognition are deeply interwoven in the fabric of the brain, suggesting that widely held beliefs about the key constituents of 'the emotional brain' and 'the cognitive brain' are fundamentally flawed.

Developing a deeper understanding will require a greater emphasis on (a) assessing the real-world relevance of laboratory assays, including measures of brain activity; (b) a network approach to characterizing the neurobiology of emotioncognition interactions, and (c) mechanistic research. Adopting these strategies mandates collaboration among researchers from different disciplines, with expertise in different species, populations, measurement tools, analytic strategies, and conceptual approaches.

Addressing the interplay of emotion and cognition is a matter of theoretical as well as practical importance. In particular, many of the most common and costly neuropsychiatric disorders-anxiety, depression, schizophrenia, substance abuse, chronic pain, autism, and so on-involve prominent disturbances of cognition and emotion (Millan, 2013). Fundamentally, they are disorders of the emotional-cognitive brain. Collectively, these disorders far outstrip the global burden of cancer or cardiovascular disease (Collins et al., 2011; Whiteford et al., 2013; DiLuca and Olesen, 2014), underscoring the importance of accelerating efforts to understand the neural systems underlying the interaction and integration of emotion and cognition.

\section{GLOSSARY OF TERMS NOT DEFINED IN THE MAIN TEXT}

Affect: The experience or expression of emotion (see also Barrett et al., 2007).

Anxiety: A sustained state of heightened apprehension in response to uncertain, distal, or diffuse threat (Davis et al., 2010).

Cognition: Cognition is a fuzzy category that conventionally includes processes involved in knowing or 'thinking,' including attention, imagination, language, learning, memory, and perception (for discussion, see Duncan and Barrett, 2007).

Emotion: Like 'cognition,' 'emotion' is a fuzzy, contentious category that conventionally includes valenced processes (e.g., action tendencies, attention, overt behavior, subjective feelings, and alterations in peripheral physiology) that are triggered by specific external or internal stimuli (e.g., actual or remembered threat for fear); often taken to include states of anger, disgust, fear, happiness, and sadness (e.g., Ekman and Davidson, 1994; Duncan and Barrett, 2007; Gendron and Barrett, 2009; LeDoux, 2012, 2014).

Mood: A low-intensity emotional state that persists in the absence of an explicit triggering stimulus (Ekman and Davidson, 1994).

Motivation: Internal states that are elicited by reinforcers and serve to organize behavioral direction (i.e., approach or avoidance) and intensity. Emotional states involve alterations in motivation (e.g., increased avoidance in the case of fear). However, motivation can be altered by homeostatic processes, such as hunger and satiety, that are not conventionally considered emotional (Rolls, 1999).

Neuroticism/Negative Emotionality: A fundamental dimension of childhood temperament and adult personality; individuals with high levels of Neuroticism/Negative Emotionality are susceptible to more intense or long-lasting negative emotions, including anger, 
anxiety, fear, guilt, and sadness (Watson and Clark, 1984; Caspi et al., 2005).

Reinforcer: Rewards and punishments; anything an organism will work to approach or avoid (Rolls, 1999).

\section{AUTHOR CONTRIBUTIONS}

All the authors supervised the Special Research Topic. Hadas Okon-Singer and Alexander J. Shackman wrote the paper. All the authors edited and revised the paper.

\section{ACKNOWLEDGMENTS}

We thank the many contributors and staff who made the Special Research Topic possible. We acknowledge the assistance of $\mathrm{L}$. Friedman and support of the European Commission (Followship \#334206 to Hadas Okon-Singer and Grant \#602186 to Talma Hendler), Israeli Center of Research Excellence, Israeli Science Foundation (Grant \#51/11 to Talma Hendler), National Institute of Mental Health (MH071589 to Luiz Pessoa), and University of Maryland (Alexander J. Shackman and Luiz Pessoa).

\section{REFERENCES}

Adachi, Y., Osada, T., Sporns, O., Watanabe, T., Matsui, T., Miyamoto, K., et al. (2012). Functional connectivity between anatomically unconnected areas is shaped by collective network-level effects in the macaque cortex. Cereb. Cortex 22, 1586-1592. doi: 10.1093/cercor/bhr234

Admon, R., Lubin, G., Rosenblatt, J. D., Stern, O., Kahn, I., Assaf, M., et al. (2012). Imbalanced neural responsivity to risk and reward indicates stress vulnerability in humans. Cereb. Cortex 23, 28-35. doi: 10.1093/cercor/bhr369

Admon, R., Lubin, G., Stern, O., Rosenberg, K., Sela, L., Ben-Ami, H., et al. (2009). Human vulnerability to stress depends on amygdala's predisposition and hippocampal plasticity. Proc. Natl. Acad. Sci. U.S.A. 106, 14120-14125. doi: 10.1073/pnas.0903183106

Admon, R., Milad, M. R., and Hendler, T. (2013). A causal model of post-traumatic stress disorder: disentangling predisposed from acquired neural abnormalities. Trends Cogn. Sci 17, 337-347. doi: 10.1016/j.tics.2013.05.005

Anticevic, A., Cole, M. W., Repovs, G., Savic, A., Driesen, N. R., Yang, G., et al. (2013). Connectivity, pharmacology, and computation: toward a mechanistic understanding of neural system dysfunction in schizophrenia. Front. Psychiatry 4:169. doi: 10.3389/fpsyt.2013.00169

Arend, I., Henik, A., and Okon-Singer, H. (2014). Dissociating emotion and attention functions in the Pulvinar nucleus of the Thalamus. Neuropsychology. doi: 10.1037/neu0000139 [Epub ahead of print].

Arnsten, A. F. (1998). The biology of being frazzled. Science 280, 1711-1712. doi: $10.1126 /$ science. 280.5370 .1711

Arnsten, A. F. (2009). Stress signalling pathways that impair prefrontal cortex structure and function. Nat. Rev. Neurosci. 10, 410-422. doi: 10.1038/ $\operatorname{nrn} 2648$

Arnsten, A. F., and Goldman-Rakic, P. S. (1998). Noise stress impairs prefrontal cortical cognitive function in monkeys: evidence for a hyperdopaminergic mechanism. Arch. Gen. Psychiatry 55, 362-368. doi: 10.1001/archpsyc.55. 4.362

Aue, T., Guex, R., Chauvigne, L. A., and Okon-Singer, H. (2013a). Varying expectancies and attention bias in phobic and non-phobic individuals. Front. Hum. Neurosci. 7:418. doi: 10.3389/fnhum.2013.00418

Aue, T., Hoeppli, M. E., Piguet, C., Sterpenich, V., and Vuilleumier, P. (2013b). Visual avoidance in phobia: particularities in neural activity, autonomic responding, and cognitive risk evaluations. Front. Hum. Neurosci. 7:194. doi: 10.3389/fnhum.2013.00194

Awh, E., and Vogel, E. K. (2008). The bouncer in the brain. Nat. Neurosci. 11, 5-6. doi: $10.1038 / \mathrm{nn} 0108-5$

Bar-Haim, Y., Lamy, D., Pergamin, L., Bakermans-Kranenburg, M. J., and Van, I. M. H. (2007). Threat-related attentional bias in anxious and nonanxious individuals: a meta-analytic study. Psychol. Bull. 133, 1-24. doi: 10.1037/00332909.133.1.1
Bar-Haim, Y., and Pine, D. S. (2013). Cognitive training research and the search for a transformative, translational, developmental cognitive neuroscience. Dev. Cogn. Neurosci. 4, 1-2. doi: 10.1016/j.dcn.2013.02.001

Barrett, L. F., Mesquita, B., Ochsner, K. N., and Gross, J. J. (2007). The experience of emotion. Annu. Rev. Psychol. 58, 373. doi: 10.1146/annurev.psych.58.110405.085709

Barrett, L. F., and Satpute, A. B. (2013). Large-scale brain networks in affective and social neuroscience: towards an integrative functional architecture of the brain. Curr. Opin. Neurobiol. 23, 361-372. doi: 10.1016/j.conb.2012.12.012

Berggren, N., and Derakshan, N. (2013). Attentional control deficits in trait anxiety: why you see them and why you don't. Biol. Psychol. 92, 440-446. doi: 10.1016/j.biopsycho.2012.03.007

Berggren, N., and Derakshan, N. (2014). Inhibitory deficits in trait anxiety: increased stimulus-based or response-based interference? Psychon. Bull. Rev. 21, 13391345. doi: 10.3758/s13423-014-0611-8

Berggren, N., Richards, A., Taylor, J., and Derakshan, N. (2013). Affective attention under cognitive load: reduced emotional biases but emergent anxiety-related costs to inhibitory control. Front. Hum. Neurosci. 7:188. doi: 10.3389/fnhum.2013.00188

Berghorst, L. H., Bogdan, R., Frank, M. J., and Pizzagalli, D. A. (2013). Acute stress selectively reduces reward sensitivity. Front. Hum. Neurosci. 7:133. doi: 10.3389/fnhum.2013.00133

Berkman, E. T., and Falk, E. B. (2013). Beyond brain mapping: using neural measures to predict real-world outcomes. Curr. Dir. Psychol. Sci. 22:45-50. doi: 10.1177/0963721412469394

Birn, R. M., Shackman, A. J., Oler, J. A., Williams, L. E., Mcfarlin, D. R., Rogers, G. M., et al. (2014a). Evolutionarily conserved prefrontal-amygdalar dysfunction in early-life anxiety. Mol. Psychiatry 19, 915-922. doi: 10.1038/mp.2014.46

Birn, R. M., Shackman, A. J., Oler, J. A., Williams, L. E., Mcfarlin, D. R., Rogers, G. M., et al. (2014b). Extreme early-life anxiety is associated with an evolutionarily conserved reduction in the strength of intrinsic functional connectivity between the dorsolateral prefrontal cortex and the central nucleus of the amygdala. Mol. Psychiatry 19, 853. doi: 10.1038/mp.2014.85

Bishop, S. J. (2007). Neurocognitive mechanisms of anxiety: an integrative account. Trends Cogn. Sci. 11, 307-316. doi: 10.1016/j.tics.2007.05.008

Bishop, S. J. (2009). Trait anxiety and impoverished prefrontal control of attention. Nat. Neurosci. 12, 92-98. doi: 10.1038/nn.2242

Bishop, S. J., and Forster, S. (2013). "Trait anxiety, neuroticism and the brain basis of vulnerability to affective disorder," in The Cambridge Handbook of Human Affective Neuroscience, eds J. Armony and P. Vuilleumier (Cambridge: Cambridge University Press), 553-574. doi: 10.1017/CBO9780511843716.031

Blackford, J. U., Avery, S. N., Shelton, R. C., and Zald, D. H. (2009). Amygdala temporal dynamics: temperamental differences in the timing of amygdala response to familiar and novel faces. BMC Neurosci. 10:145. doi: 10.1186/1471-2202-10-145

Blackford, J. U., and Pine, D. S. (2012). Neural substrates of childhood anxiety disorders: a review of neuroimaging findings. Child Adolesc. Psychiatr. Clin. N. Am. 21, 501-525. doi: 10.1016/j.chc.2012.05.002

Bogdan, R., Perlis, R. H., Fagerness, J., and Pizzagalli, D. A. (2010). The impact of mineralocorticoid receptor ISO/VAL genotype (rs5522) and stress on reward learning. Genes Brain Behav. 9, 658-667. doi: 10.1111/j.1601-183X.2010. 00600.x

Bogdan, R., and Pizzagalli, D. A. (2006). Acute stress reduces reward responsiveness: implications for depression. Biol. Psychiatry 60, 1147-1154. doi: 10.1016/j.biopsych.2006.03.037

Bolger, N., and Schilling, E. A. (1991). Personality and the problems of everyday life: the role of neuroticism in exposure and reactivity to daily stressors. J. Pers. 59, 355-386. doi: 10.1111/j.1467-6494.1991.tb00253.x

Borsook, D., Becerra, L., and Hargreaves, R. (2006). A role for fMRI in optimizing CNS drug development. Nat. Rev. Drug Discov. 5, 411-424. doi: 10.1038/ $\operatorname{nrd} 2027$

Botvinick, M. M. (2007). Conflict monitoring and decision making: reconciling two perspectives on anterior cingulate function. Cogn. Affect. Behav. Neurosci. 7, 356-366. doi: 10.3758/CABN.7.4.356

Braver, T. S., Krug, M. K., Chiew, K. S., Kool, W., Westbrook, J. A., Clement, N. J., et al. (2014). Mechanisms of motivation-cognition interaction: challenges and opportunities. Cogn. Affect. Behav. Neurosci. 14, 443-472. doi: 10.3758/s13415014-0300-0

Buhle, J. T., Silvers, J. A., Wager, T. D., Lopez, R., Onyemekwu, C., Kober, H., et al. (2013). Cognitive reappraisal of emotion: a meta-analysis of human 
neuroimaging studies. Cereb. Cortex 24, 2981-2990. doi: 10.1093/cercor/ bht154

Bullmore, E., and Sporns, O. (2012). The economy of brain network organization. Nat. Rev. Neurosci. 13, 336-349. doi: 10.1038/nrn3214

Button, K. S., Ioannidis, J. P., Mokrysz, C., Nosek, B. A., Flint, J., Robinson, E. S., et al. (2013a). Confidence and precision increase with high statistical power. Nat. Rev. Neurosci. 14, 585-586. doi: 10.1038/nrn3475-c4

Button, K. S., Ioannidis, J. P., Mokrysz, C., Nosek, B. A., Flint, J., Robinson, E. S., et al. (2013b). Empirical evidence for low reproducibility indicates low pre-study odds. Nat. Rev. Neurosci. 14, 877. doi: 10.1038/nrn3475-c6

Button, K. S., Ioannidis, J. P., Mokrysz, C., Nosek, B. A., Flint, J., Robinson, E. S., et al. (2013c). Power failure: why small sample size undermines the reliability of neuroscience. Nat. Rev. Neurosci. 14, 365-376. doi: 10.1038/nrn3475

Campbell, D. T., and Fiske, D. W. (1959). Convergent and discriminant validation by the multitrait-multimethod matrix. Psychol. Bull. 56, 81-105. doi: $10.1037 / \mathrm{h} 0046016$

Canli, T., Omura, K., Haas, B. W., Fallgatter, A., Constable, R. T., and Lesch, K. P. (2005). Beyond affect: a role for genetic variation of the serotonin transporter in neural activation during a cognitive attention task. Proc. Natl. Acad. Sci. U.S.A 102, 12224-12229. doi: 10.1073/pnas.0503880102

Carretié, L. (2014). Exogenous (automatic) attention to emotional stimuli: a review. Cogn. Affect. Behav. Neurosci. 14, 1228-1258. doi: 10.3758/s13415-014-0270-2

Casey, B., Craddock, N., Cuthbert, B. N., Hyman, S. E., Lee, F. S., and Ressler, K. J. (2013). DSM-5 and RDoC: progress in psychiatry research? Nat. Rev. Neurosci. 14, 810-814. doi: 10.1038/nrn3621

Caspi, A., Roberts, B. W., and Shiner, R. L. (2005). Personality development: stability and change. Annu. Rev. Psychol. 56, 453-484. doi: 10.1146/annurev.psych.55.090902.141913

Cavanagh, J. F., and Shackman, A. J. (2014). Frontal midline theta reflects anxiety and cognitive control: meta-analytic evidence. J. Physiol. Paris. doi: 10.1016/j.jphysparis.2014.04.003 [Epub ahead of print].

Chalmers, I., Bracken, M. B., Djulbegovic, B., Garattini, S., Grant, J., Gulmezoglu, A. M., etal. (2014). How to increase value and reduce waste when research priorities are set. Lancet 383, 156-165. doi: 10.1016/S0140-6736(13) 62229-1

Chen, A. C., Oathes, D. J., Chang, C., Bradley, T., Zhou, Z. -W., Williams, L. M., et al (2013). Causal interactions between fronto-parietal central executive and defaultmode networks in humans. Proc. Natl. Acad. Sci. U.S.A. 110, 19944-19949. doi: $10.1073 /$ pnas. 1311772110

Clarke, R., and Johnstone, T. (2013). Prefrontal inhibition of threat processing reduces working memory interference. Front. Hum. Neurosci. 7:228. doi: $10.3389 /$ fnhum. 2013.00228

Coan, J. A., and Allen, J. J. B. (2007). Handbook of Emotion Elicitation and Assessment. New York: Oxford University Press.

Cohen, N., Daches, S., Mor, N., and Henik, A. (2014). Inhibition of negative content-a shared process in rumination and reappraisal. Front. Psychol. 5:622. doi: 10.3389/fpsyg.2014.00622

Collins, P. Y., Patel, V., Joestl, S. S., March, D., Insel, T. R., Daar, A. S., et al (2011). Grand challenges in global mental health. Nature 475, 27-30. doi: $10.1038 / 475027 \mathrm{a}$

Crocker, L. D., Heller, W., Warren, S. L., O’hare, A. J., Infantolino, Z. P., and Miller, G. A. (2013). Relationships among cognition, emotion, and motivation: implications for intervention and neuroplasticity in psychopathology. Front. Hum. Neurosci. 7:261. doi: 10.3389/fnhum.2013.00261

Dalton, K. M., Nacewicz, B. M., Alexander, A. L., and Davidson, R. J. (2007). Gazefixation, brain activation, and amygdala volume in unaffected siblings of individuals with autism. Biol. Psychiatry 61, 512-520. doi: 10.1016/j.biopsych.2006. 05.019

Dalton, K. M., Nacewicz, B. M., Johnstone, T., Schaefer, H. S., Gernsbacher, M. A., Goldsmith, H. H., et al. (2005). Gaze fixation and the neural circuitry of face processing in autism. Nat. Neurosci. 8, 519-526. doi: 10.1038/nn1421

Damasio, A. (2005a). Descartes' Error: Emotion, Reason, and the Human Brain. New York, NY: Penguin.

Damasio, A. (2005b). Human behaviour: brain trust. Nature 435, 571-572. doi: $10.1038 / 435571 \mathrm{a}$

Darwin, C. (1872/2009). The Expression of the Emotions in Man and Animals, 4th Edn. New York, NY: Oxford University Press.

Darwin, C. (1872). The Origin of Species. London: John Murray.
David, S. P., Ware, J. J., Chu, I. M., Loftus, P. D., Fusar-Poli, P., Radua, J., et al. (2013). Potential reporting bias in fMRI studies of the brain. PLoS ONE 8:e70104. doi: 10.1371/journal.pone.0070104

Davidson, R. J. (2004). Well-being and affective style: neural substrates and biobehavioural correlates. Philos. Trans. R. Soc. Lond. B Biol. Sci. 359, 1395-1411. doi: 10.1098/rstb.2004.1510

Davis, M., Walker, D. L., Miles, L., and Grillon, C. (2010). Phasic vs sustained fear in rats and humans: role of the extended amygdala in fear vs anxiety. Neuropsychopharmacology 35, 105-135. doi: 10.1038/npp.2009.109

Davis, M., and Whalen, P. J. (2001). The amygdala: vigilance and emotion. Mol. Psychiatry 6, 13-34. doi: 10.1038/sj.mp.4000812

D'Esposito, M., and Postle, B. R. (2014). The cognitive neuroscience of working memory. Annu. Rev. Psychol. 66, 115-142. doi: 10.1146/annurev-psych-010814015031

de Sousa, R. (2014). "Emotion," in Stanford Encyclopedia of Philosophy, ed. E. N. Zalta (Stanford, CA: Stanford University). Available at: http://plato.stanford.edu/entries/emotion/

Desai, M., Kahn, I., Knoblich, U., Bernstein, J., Atallah, H., Yang, A., et al. (2011). Mapping brain networks in awake mice using combined optical neural control and fMRI. J. Neurophysiol. 105, 1393-1405. doi: 10.1152/jn.00828.2010

Desimone, R., and Duncan, J. (1995). Neural mechanisms of selective visual attention. Annu. Rev. Neurosci. 18, 193-222. doi: 10.1146/annurev.ne.18.030195. 001205

DiLuca, M., and Olesen, J. (2014). The cost of brain diseases: a burden or a challenge? Neuron 82, 1205-1208. doi: 10.1016/j.neuron.2014.05.044

Dolcos, F., and Denkova, E. (2014). Current emotion research in cognitive neuroscience: linking enhancing and impairing effects of emotion on cognition. Emot. Rev. 6, 362-375. doi: 10.1177/1754073914536449

Dreisbach, G., and Fischer, R. (2012). The role of affect and reward in the conflicttriggered adjustment of cognitive control. Front. Hum. Neurosci. 6:342. doi: 10.3389/fnhum.2012.00342

Duncan, S., and Barrett, L. F. (2007). Affect is a form of cognition: a neurobiological analysis. Cogn. Emot. 21, 1184-1211. doi: 10.1080/026999307014 37931

Egeth, H. E., and Yantis, S. (1997). Visual attention: control, representation, and time course. Annu. Rev. Psychol. 48, 269-297. doi: 10.1146/annurev.psych.48.1.269

Egloff, B., Schmukle, S. C., Burns, L. R., and Schwerdtfeger, A. (2006). Spontaneous emotion regulation during evaluated speaking tasks: associations with negative affect, anxiety expression, memory, and physiological responding. Emotion 6, 356-366. doi: 10.1037/1528-3542.6.3.356

Ehring, T., Tuschen-Caffier, B., Schnulle, J., Fischer, S., and Gross, J. J. (2010). Emotion regulation and vulnerability to depression: spontaneous versus instructed use of emotion suppression and reappraisal. Emotion 10, 563-572. doi: 10.1037/a0019010

Ekman, P. E., and Davidson, R. J. (1994). The nature of Emotion: Fundamental Questions. Oxford: Oxford University Press.

Ekstrom, L. B., Roelfsema, P. R., Arsenault, J. T., Bonmassar, G., and Vanduffel, W. (2008). Bottom-up dependent gating of frontal signals in early visual cortex. Science 321, 414-417. doi: 10.1126/science.1153276

Etkin, A. (2012). Neurobiology of anxiety: from neural circuits to novel solutions? Depress Anxiety 29, 355-358. doi: 10.1002/da.21957

Etkin, A., Gyurak, A., and O'hara, R. (2013). A neurobiological approach to the cognitive deficits of psychiatric disorders. Dialogues Clin. Neurosci. 15, 419-429.

Eysenck, M. W., Derakshan, N., Santos, R., and Calvo, M. G. (2007). Anxiety and cognitive performance: attentional control theory. Emotion 7, 336-353. doi: 10.1037/1528-3542.7.2.336

Forbes, E. E., Hariri, A. R., Martin, S. L., Silk, J. S., Moyles, D. L., Fisher, P. M., et al. (2009). Altered striatal activation predicting real-world positive affect in adolescent major depressive disorder. Am. J. Psychiatry 166, 64-73. doi: 10.1176/appi.ajp.2008.07081336

Fox, A. S., and Kalin, N. H. (2014). A translational neuroscience approach to understanding the development of social anxiety disorder and its pathophysiology. Am. J. Psychiatry doi: 10.1176/appi.ajp.2014.14040449 [Epub ahead of print].

Fox, A. S., Oler, J. A., Shelton, S. E., Nanda, S. A., Davidson, R. J., Roseboom, P. H., et al. (2012). Central amygdala nucleus (Ce) gene expression linked to increased trait-like Ce metabolism and anxious temperament in young primates. Proc. Natl. Acad. Sci. U.S.A. 109, 18108-18113. doi: 10.1073/pnas.1206 723109 
Fox, A. S., Shelton, S. E., Oakes, T. R., Converse, A. K., Davidson, R. J., and Kalin, N. H. (2010). Orbitofrontal cortex lesions alter anxiety-related activity in the primate bed nucleus of stria terminalis. J. Neurosci. 30, 7023-7027. doi: 10.1523/JNEUROSCI.5952-09.2010

Fox, A. S., Shelton, S. E., Oakes, T. R., Davidson, R. J., and Kalin, N. H. (2008). Traitlike brain activity during adolescence predicts anxious temperament in primates. PLoS ONE 3:e2570. doi: 10.1371/journal.pone.0002570

Fox, N. A., Henderson, H. A., Marshall, P. J., Nichols, K. E., and Ghera, M. M. (2005a). Behavioral inhibition: linking biology and behavior within a developmental framework. Annu. Rev. Psychol. 56, 235-262. doi: 10.1146/annurev.psych.55.090902.141532

Fox, A. S., Oakes, T. R., Shelton, S. E., Converse, A. K., Davidson, R. J., and Kalin, N. H. (2005b). Calling for help is independently modulated by brain systems underlying goal-directed behavior and threat perception. Proc. Natl. Acad. Sci. U.S.A. 102, 4176-4179. doi: 10.1073/pnas.0409470102

Frank, D. W., Dewitt, M., Hudgens-Haney, M., Schaeffer, D. J., Ball, B. H., Schwarz N. F., et al. (2014). Emotion regulation: quantitative meta-analysis of functional activation and deactivation. Neurosci. Biobehav. Rev. 45C, 202-211. doi: 10.1016/j.neubiorev.2014.06.010

Gendron, M., and Barrett, L. F. (2009). Reconstructing the past: a century of ideas about emotion in psychology. Emot. Rev. 1, 316-339. doi: $10.1177 / 1754073909338877$

Goldman-Rakic, P. S. (1988). Topography of cognition: parallel distributed networks in primate association cortex. Annu. Rev. Neurosci. 11, 137-156. doi: 10.1146/annurev.ne.11.030188.001033

Gosling, S. D., and Mason, W. (2015). Internet research in psychology. Annu. Rev. Psychol. 66, 877-902. doi: 10.1146/annurev-psych-010814-015321

Gratton, C., Nomura, E. M., Perez, F., and D'esposito, M. (2012). Focal brain lesions to critical locations cause widespread disruption of the modular organization of the brain. J. Cogn. Neurosci. 24, 1275-1285. doi: 10.1162/jocn-a00222

Gray, J. A., and McNaughton, N. (2000). The Neuropsychology of Anxiety: An Enquiry into the Functions of the Septo-Hippocampal System. Oxford: Oxford Psychology Press.

Gross, J. J. (1998a). Antecedent- and response-focused emotion regulation: divergent consequences for experience, expression, and physiology. J. Pers. Soc. Psychol 74, 224-237. doi: 10.1037/0022-3514.74.1.224

Gross, J. J. (1998b). The emerging field of emotion regulation: an integrative review. Rev. Gen. Psychol. 2, 271. doi: 10.1037/1089-2680.2.3.271

Gross, J. J., Sheppes, G., and Urry, H. L. (2011). Cognition and emotion lecture at the 2010 spsp emotion preconference. Cogn. Emot. 25, 765-781. doi: $10.1080 / 02699931.2011 .555753$

Gross, J. J., and Thompson, R. A. (2007). "Emotion regulation: conceptual foundations," in Handbook of Emotion Regulation. Guilford: Guilford Press. 3,24 .

Grupe, D. W., and Nitschke, J. B. (2013). Uncertainty and anticipation in anxiety: an integrated neurobiological and psychological perspective. Nat. Rev. Neurosci. 14, 488-501. doi: 10.1038/nrn3524

Guller, Y., Tononi, G., and Postle, B. R. (2012). Conserved functional connectivity but impaired effective connectivity of thalamocortical circuitry in schizophrenia. Brain Connect. 2, 311-319. doi: 10.1089/brain.2012.0100

Hajcak, G., and Olvet, D. M. (2008). The persistence of attention to emotion: brain potentials during and after picture presentation. Emotion 8, 250-255. doi: $10.1037 / 1528-3542.8 .2 .250$

Hakamata, Y., Lissek, S., Bar-Haim, Y., Britton, J. C., Fox, N. A., Leibenluft, E., et al. (2010). Attention bias modification treatment: a meta-analysis toward the establishment of novel treatment for anxiety. Biol. Psychiatry 68, 982-990. doi: 10.1016/j.biopsych.2010.07.021

Hare, T. A., Camerer, C. F., and Rangel, A. (2009). Self-control in decision-making involves modulation of the vmPFC valuation system. Science 324, 646-648. doi: $10.1126 /$ science. 1168450

Hare, T. A., O’Doherty, J., Camerer, C. F., Schultz, W., and Rangel, A. (2008). Dissociating the role of the orbitofrontal cortex and the striatum in the computation of goal values and prediction errors. J. Neurosci. 28, 5623-5630. doi: 10.1523/JNEUROSCI.1309-08.2008

Harlé, K. M., Shenoy, P., and Paulus, M. P. (2013). The influence of emotions on cognitive control: feelings and beliefs-where do they meet? Front. Hum. Neurosci. 7:508. doi: 10.3389/fnhum.2013.00508
Hartley, C. A., and Phelps, E. A. (2012). Anxiety and decision-making. Biol. Psychiatry 72, 113-118. doi: 10.1016/j.biopsych.2011.12.027

Heller, A. S., Lapate, R. C., Mayer, K. E., and Davidson, R. J. (2014). The face of negative affect: trial-by-trial corrugator responses to negative pictures are positively associated with amygdala and negatively associated with ventromedial prefrontal cortex activity. J. Cogn. Neurosci. 26, 2102-2110. doi: 10.1162/jocn-a-00622

Henderson, H. A., Pine, D. S., and Fox, N. A. (2014). Behavioral inhibition and developmental risk: a dual-processing perspective. Neuropsychopharmacology. 40, 207-224. doi: 10.1038/npp.2014.189

Holtmann, J., Herbort, M. C., Wustenberg, T., Soch, J., Richter, S., Walter, H., et al. (2013). Trait anxiety modulates fronto-limbic processing of emotional interference in borderline personality disorder. Front. Hum. Neurosci. 7:54. doi: 10.3389/fnhum.2013.00054

Honey, C. J., Sporns, O., Cammoun, L., Gigandet, X., Thiran, J. P., Meuli, R., et al. (2009). Predicting human resting-state functional connectivity from structural connectivity. Proc. Natl. Acad. Sci. U.S.A. 106, 2035-2040. doi: 10.1073/pnas.0811168106

Ioannidis, J. P., Greenland, S., Hlatky, M. A., Khoury, M. J., Macleod, M. R., Moher, D., et al. (2014a). Increasing value and reducing waste in research design, conduct, and analysis. Lancet 383, 166-175. doi: 10.1016/S0140-6736(13) 62227-8

Ioannidis, J. P., Munafo, M. R., Fusar-Poli, P., Nosek, B. A., and David, S. P. (2014b). Publication and other reporting biases in cognitive sciences: detection, prevalence, and prevention. Trends Cogn. Sci. 18, 235-241. doi: 10.1016/j.tics.2014.02.010

Iordan, A. D., Dolcos, S., and Dolcos, F. (2013). Neural signatures of the response to emotional distraction: a review of evidence from brain imaging investigations. Front. Hum. Neurosci. 7:200. doi: 10.3389/fnhum.2013.00200

John, Y. J., Bullock, D., Zikopoulos, B., and Barbas, H. (2013). Anatomy and computational modeling of networks underlying cognitive-emotional interaction. Front. Hum. Neurosci. 7:101. doi: 10.3389/fnhum.2013.00101

Johnson, J. S., Kundu, B., Casali, A. G., and Postle, B. R. (2012). Task-dependent changes in cortical excitability and effective connectivity: a combined TMS-EEG study. J. Neurophysiol. 107, 2383-2392. doi: 10.1152/jn.00707.2011

Kalanthroff, E., Cohen, N., and Henik, A. (2013). Stop feeling: inhibition of emotional interference following stop-signal trials. Front. Hum. Neurosci. 7:78. doi: $10.3389 /$ fnhum. 2013.00078

Karnath, H. O., and Smith, D. V. (2014). The next step in modern brain lesion analysis: multivariate pattern analysis. Brain 137, 2405-2407. doi: 10.1093/brain/awu180

Kendler, K. S., and Gardner, C. O. (2014). Sex differences in the pathways to major depression: a study of opposite-sex twin pairs. Am. J. Psychiatry 171, 426-435. doi: 10.1176/appi.ajp.2013.13101375

Kessel, E. M., Huselid, R. F., Decicco, J. M., and Dennis, T. A. (2013). Neurophysiological processing of emotion and parenting interact to predict inhibited behavior: an affective-motivational framework. Front. Hum. Neurosci. 7:326. doi: 10.3389/fnhum.2013.00326

Kessler, R. C., Petukhova, M., Sampson, N. A., Zaslavsky, A. M., and Wittchen, H. U. (2012). Twelve month and lifetime prevalence and lifetime morbid risk of anxiety and mood disorders in the United States. Int. J. Methods Psychiatr. Res. 21, 169-184. doi: 10.1002/mpr.1359

Kinnison, J., Padmala, S., Choi, J.-M., and Pessoa, L. (2012). Network analysis reveals increased integration during emotional and motivational processing. J. Neurosci. 32, 8361-8372. doi: 10.1523/JNEUROSCI.0821-12.2012

Koenigs, M., Huey, E. D., Calamia, M., Raymont, V., Tranel, D., and Grafman, J. (2008). Distinct regions of prefrontal cortex mediate resistance and vulnerability to depression. J. Neurosci. 28, 12341-12348. doi: 10.1523/JNEUROSCI.232408.2008

Kool, W., Mcguire, J. T., Rosen, Z. B., and Botvinick, M. M. (2010). Decision making and the avoidance of cognitive demand. J. Exp. Psychol. Gen. 139, 665. doi: $10.1037 / \mathrm{a} 0020198$

Lapate, R. C., Van Reekum, C. M., Schaefer, S. M., Greischar, L. L., Norris, C. J., Bachhuber, D. R., et al. (2014). Prolonged marital stress is associated with short-lived responses to positive stimuli. Psychophysiology 51, 499-509. doi: $10.1111 /$ psyp. 12203

LeDoux, J. E. (1995). Emotion: clues from the brain. Annu. Rev. Psychol. 46, 209-235. doi: 10.1146/annurev.ps.46.020195.001233

LeDoux, J. E. (2012). Rethinking the emotional brain. Neuron 73, 653-676. doi: 10.1016/j.neuron.2012.02.004 
LeDoux, J. E. (2014). Coming to terms with fear. Proc. Natl. Acad. Sci. U.S.A. 111, 2871-2878. doi: 10.1073/pnas.1400335111

Lee, H., Shackman, A. J., Jackson, D. C., and Davidson, R. J. (2009). Test-retest reliability of voluntary emotion regulation. Psychophysiology 46, 874-879. doi: 10.1111/j.1469-8986.2009.00830.x

Lee, J. H., Durand, R., Gradinaru, V., Zhang, F., Goshen, I., Kim, D. S., et al. (2010). Global and local fMRI signals driven by neurons defined optogenetically by type and wiring. Nature 465, 788-792. doi: 10.1038/nature09108

Lerman, C., LeSage, M. G., Perkins, K. A., O’Malley, S. S., Siegel, S. J., Benowitz, N. L., et al. (2007). Translational research in medication development for nicotine dependence. Nat. Rev. Drug Discov. 6, 746-762. doi: 10.1038/nrd2361

Lerner, J. S., Li, Y., Valdesolo, P., and Kassam, K. S. (2015). Emotion and decision making. Annu. Rev. Psychol. 66, 33.1-33.25.

Lerner, Y., Singer, N., Gonen, T., Weintraub, Y., Cohen, O., Rubin, N., et al. (2012). Feeling without seeing? Engagement of ventral, but not dorsal, amygdala during unaware exposure to emotional faces. J. Cogn. Neurosci. 24, 531-542. doi: 10.1162/jocn-a-00165

Levenson, R. W. (1994). "I. Human emotion: a functional view. II. The search for autonomic specificity. III. Emotional control: variation and consequences," in The Nature of Emotion. Fundamental Questions, eds P. Ekman and R. Davidson (New York: Oxford University Press).

Lewis-Peacock, J. A., and Norman, K. A. (2013). Multi-voxel pattern analysis of fMRI data: a review. Comput. Math. Methods Med. 2012, 1-14.

Lin, T., Vaisvaser, S., Fruchter, E., Admon, R., Wald, I., Pine, D., et al. (2014). A neurobehavioral account for individual differences in resilience to chronic military stress. Psychol. Med. 1-13. doi: 10.1017/S0033291714002013

Lindquist, K. A., and Barrett, L. F. (2012). A functional architecture of the human brain: emerging insights from the science of emotion. Trends Cogn. Sci. 16, 533-540. doi: 10.1016/j.tics.2012.09.005

Lindström, B. R., Mattsson-Mårn, I. B., Golkar, A., and Olsson, A. (2013). In your face: risk of punishment enhances cognitive control and errorrelated activity in the corrugator supercilii muscle. PLOS ONE 8:e65692. doi: 10.1371/journal.pone.0065692

Lissek, S. (2012). Toward an account of clinical anxiety predicated on basic, neurally mapped mechanisms of Pavlovian fear-learning: the case for conditioned overgeneralization. Depress. Anxiety 29, 257-263. doi: 10.1002/da.21922

Logothetis, N. K. (2008). What we can do and what we cannot do with fMRI. Nature 453, 869-878. doi: 10.1038/nature06976

Lopez, R. B., Hofmann, W., Wagner, D. D., Kelley, W. M., and Heatherton, T. F. (2014). Neural predictors of giving in to temptation in daily life. Psychol. Sci. 25, 1337-1344. doi: 10.1177/0956797614531492

MacLeod, C., and Clarke, P. J. (2015). The attentional bias modification approach to anxiety intervention. Clin. Psychol. Sci. 3, 58-78. doi: 10.1177/2167702614560749

MacLeod, C., and Mathews, A. (2012). Cognitive bias modification approaches to anxiety. Annu. Rev. Clin. Psychol. 8, 189-217. doi: 10.1146/annurev-clinpsy032511-143052

Matthews, G., Deary, I. J., and Whiteman, M. C. (2009). Personality Traits, 3rd Edn. Cambridge: Cambridge University Press. doi: 10.1017/CBO97805118 12743

McDermott, J. M., Troller-Renfree, S., Vanderwert, R., Nelson, C. A., Zeanah, C. H., and Fox, N. A. (2013). Psychosocial deprivation, executive functions, and the emergence of socio-emotional behavior problems. Front. Hum. Neurosci. 7:167. doi: 10.3389/fnhum.2013.00167

McHugo, M., Olatunji, B. O., and Zald, D. H. (2013). The emotional attentional blink: what we know so far. Front. Hum. Neurosci. 7:151. doi: 10.3389/fnhum.2013.00151

McMenamin, B. W., Langeslag, S. J., Sirbu, M., Padmala, S., and Pessoa, L. (2014). Network organization unfolds over time during periods of anxious anticipation. J. Neurosci. 34, 11261-11273. doi: 10.1523/JNEUROSCI.1579-14.2014

McNab, F., and Klingberg, T. (2007). Prefrontal cortex and basal ganglia control access to working memory. Nat. Neurosci. 11, 103-107. doi: 10.1038/nn2024

Mesulam, M. M. (1998). From sensation to cognition. Brain 121, 1013-1052. doi: 10.1093/brain/121.6.1013

Millan, M. J. (2013). An epigenetic framework for neurodevelopmental disorders: from pathogenesis to potential therapy. Neuropharmacology 68, 2-82. doi: 10.1016/j.neuropharm.2012.11.015

Miller, E. K., and Cohen, J. D. (2001). An integrative theory of prefrontal cortex function. Annu. Rev. Neurosci. 24, 167-202. doi: 10.1146/annurev.neuro.24.1.167
Mohanty, A., and Sussman, T. J. (2013). Top-down modulation of attention by emotion. Front. Hum. Neurosci. 7:102. doi: 10.3389/fnhum.2013.00102

Montague, P. R., Dolan, R. J., Friston, K. J., and Dayan, P. (2012). Computational psychiatry. Trends Cogn. Sci. 16, 72-80. doi: 10.1016/j.tics.2011.11.018

Morrison, I., Perini, I., and Dunham, J. (2013). Facets and mechanisms of adaptive pain behavior: predictive regulation and action. Front. Hum. Neurosci. 7:755. doi: 10.3389/fnhum.2013.00755

Morriss, J., Taylor, A. N., Roesch, E. B., and Van Reekum, C. M. (2013). Still feeling it: the time course of emotional recovery from an attentional perspective. Front. Hum. Neurosci. 7:201. doi: 10.3389/fnhum.2013.00201

Moser, J. S., Moran, T. P., Schroder, H. S., Donnellan, M. B., and Yeung, N. (2013). On the relationship between anxiety and error monitoring: a meta-analysis and conceptual framework. Front. Hum. Neurosci. 7:466. doi: 10.3389/fnhum.2013.00466

Motzkin, J. C., Philippi, C. L., Wolf, R. C., Baskaya, M. K., and Koenigs, M. (2014). Ventromedial prefrontal cortex lesions alter neural and physiological correlates of anticipation. J. Neurosci. 34, 10430-10437. doi: 10.1523/JNEUROSCI.144614.2014

Murphy, K. P. (2012). Machine Learning: A Probabilistic Perspective. Cambridge, MA: MIT press.

Narayanan, N. S., Cavanagh, J. F., Frank, M. J., and Laubach, M. (2013). Common medial frontal mechanisms of adaptive control in humans and rodents. Nat. Neurosci. 16, 1888-1895. doi: 10.1038/nn.3549

Nomura, E. M., Gratton, C., Visser, R. M., Kayser, A., Perez, F., and D’esposito, M. (2010). Double dissociation of two cognitive control networks in patients with focal brain lesions. Proc. Natl. Acad. Sci. U.S.A. 107, 12017-12022. doi: 10.1073/pnas.1002431107

Norman, D. A., and Shallice, T. (1986). "Attention to action. Willed and automatic control of behavior," in Consciousness and Self-Regulation: Advances in Research and Theory, eds R. J. Davidson, G. E. Schwartz, and D. Shapiro (New York, NY: Plenum Press), 1-18.

Okon-Singer, H., Alyagon, U., Kofman, O., Tzelgov, J., and Henik, A. (2011). Fearrelated pictures deteriorate the performance of university students with high fear of snakes or spiders. Stress 14, 185-193. doi: 10.3109/10253890.2010.527401

Okon-Singer, H., Lichtenstein-Vidne, L., and Cohen, N. (2013). Dynamic modulation of emotional processing. Biol. Psychol. 92, 480-491. doi: 10.1016/j.biopsycho. 2012.05.010

Okon-Singer, H., Mehnert, J., Hoyer, J., Hellrung, L., Schaare, H. L., Dukart, J., et al. (2014a). Neural control of vascular reactions: impact of emotion and attention. J. Neurosci. 34, 4251-4259. doi: 10.1523/JNEUROSCI.0747-13.2014

Okon-Singer, H., Pessoa, L., Hendler, T., and Shackman, A. J. (2014b). Introduction to the special research topic on the neurobiology of emotioncognition interactions. Front. Hum. Neurosci. 8:1051. doi: 10.3389/fnhum.2014. 01051

Okon-Singer, H., Tzelgov, J., and Henik, A. (2007). Distinguishing between automaticity and attention in the processing of emotionally significant stimuli. Emotion 7, 147-157. doi: 10.1037/1528-3542.7.1.147

Oler, J. A., Fox, A. S., Shackman, A. J., and Kalin, N. H. (in press). "The central nucleus of the amygdala is a critical substrate for individual differences in anxiety," in Living Without an Amygdala, eds D. G. Amaral, M. Bauman, and R. Adolphs (New York, NY: Guilford Press).

Paulus, M. P., Feinstein, J. S., Leland, D., and Simmons, A. N. (2005). Superior temporal gyrus and insula provide response and outcome-dependent information during assessment and action selection in a decision-making situation. Neuroimage 25, 607-615. doi: 10.1016/j.neuroimage.2004.12.055

Peers, P. V., Simons, J. S., and Lawrence, A. D. (2013). Prefrontal control of attention to threat. Front. Hum. Neurosci. 7:24. doi: 10.3389/fnhum.2013.00024

Pessoa, L. (2012). Beyond brain regions: network perspective of cognitionemotion interactions. Behav. Brain Sci. 35, 158-159. doi: 10.1017/S0140525X110 01567

Pessoa, L. (2013). The Cognitive-Emotional Brain: From Interactions to Integration. Cambridge: MIT Press. doi: 10.7551/mitpress/9780262019569. 001.0001

Pessoa, L., and Adolphs, R. (2010). Emotion processing and the amygdala: from a 'low road' to 'many roads' of evaluating biological significance. Nat. Rev. Neurosci. 11, 773-783. doi: 10.1038/nrn2920

Pessoa, L., Mckenna, M., Gutierrez, E., and Ungerleider, L. G. (2002). Neural processing of emotional faces requires attention. Proc. Natl. Acad. Sci. U.S.A. 99, 11458-11463. doi: 10.1073/pnas.172403899 
Pessoa, L., Padmala, S., Kenzer, A., and Bauer, A. (2012). Interactions between cognition and emotion during response inhibition. Emotion 12, 192-197. doi: 10.1037/a0024109

Pizzagalli, D. A. (2014). Depression, stress, and anhedonia: toward a synthesis and integrated model. Annu. Rev. Clin. Psychol. 10, 393-423. doi: 10.1146/annurevclinpsy-050212-185606

Pizzagalli, D. A., Bogdan, R., Ratner, K. G., and Jahn, A. L. (2007). Increased perceived stress is associated with blunted hedonic capacity: potential implications for depression research. Behav. Res. Ther. 45, 2742-2753. doi: 10.1016/j.brat.2007.07.013

Pochon, J. B., Riis, J., Sanfey, A. G., Nystrom, L. E., and Cohen, J. D. (2008). Functional imaging of decision conflict. J. Neurosci. 28, 3468-3473. doi: 10.1523/JNEUROSCI.4195-07.2008

Postle, B. R. (2006). Working memory as an emergent property of the mind and brain. Neuroscience 139, 23-38. doi: 10.1016/j.neuroscience.2005.06.005

Pourtois, G., Schettino, A., and Vuilleumier, P. (2013). Brain mechanisms for emotional influences on perception and attention: what is magic and what is not. Biol. Psychol. 92, 492-512. doi: 10.1016/j.biopsycho.2012.02.007

Proudfit, G. H., Inzlicht, M., and Mennin, D. S. (2013). Anxiety and error monitoring: the importance of motivation and emotion. Front. Hum. Neurosci. 7:636. doi: 10.3389/fnhum.2013.00636

Qin, S., Hermans, E. J., van Marle, H. J., Luo, J., and Fernández, G. (2009). Acute psychological stress reduces working memory-related activity in the dorsolateral prefrontal cortex. Biol. Psychiatry 66, 25-32. doi: 10.1016/j.biopsych.2009.03.006

Raz, G., Jacob, Y., Gonen, T., Winetraub, Y., Flash, T., Soreq, E., et al. (2014). Cry for her or cry with her: context-dependent dissociation of two modes of cinematic empathy reflected in network cohesion dynamics. Soc. Cogn. Affect. Neurosci. 9, 30-38. doi: 10.1093/scan/nst052

Raz, G., Winetraub, Y., Jacob, Y., Kinreich, S., Maron-Katz, A., Shaham, G., et al. (2012). Portraying emotions at their unfolding: a multilayered approach for probing dynamics of neural networks. Neuroimage 60, 1448-1461. doi: 10.1016/j.neuroimage.2011.12.084

Reinhart, R. M., and Woodman, G. F. (2014). Oscillatory coupling reveals the dynamic reorganization of large-scale neural networks as cognitive demands change. J. Cogn. Neurosci. 26, 175-188. doi: 10.1162/jocn-a-00470

Roberts, A. C., Robbins, T. W., and Weiskrantz, L. E. (1998). The Prefrontal Cortex: Executive and Cognitive Functions. Oxford: Oxford University Press. doi: 10.1093/acprof:oso/9780198524410.001.0001

Robinson, O. J., Krimsky, M., and Grillon, C. (2013a). The impact of induced anxiety on response inhibition. Front. Hum. Neurosci. 7:69. doi 10.3389/fnhum.2013.00069

Robinson, O. J., Vytal, K., Cornwell, B. R., and Grillon, C. (2013b). The impact of anxiety upon cognition: perspectives from human threat of shock studies. Front. Hum. Neurosci. 7:203. doi: 10.3389/fnhum.2013.00203

Rohr, C. S., Okon-Singer, H., Craddock, R. C., Villringer, A., and Margulies, D. S. (2013). Affect and the brain's functional organization: a resting-state connectivity approach. PLoS ONE 8:e68015. doi: 10.1371/journal.pone.0068015

Rolls, E. T. (1999). The Brain and Emotion. Oxford: Oxford University Press.

Rolls, E. T. (2013). A biased activation theory of the cognitive and attentional modulation of emotion. Front. Hum. Neurosci. 7:74. doi: 10.3389/fnhum.2013.00074

Roseboom, P. H., Nanda, S. A., Fox, A. S., Oler, J. A., Shackman, A. J., Shelton, S. E., et al. (2014). Neuropeptide $Y$ receptor gene expression in the primate amygdala predicts anxious temperament and brain metabolism. Biol. Psychiatry 76, 850 857. doi: 10.1016/j.biopsych.2013.11.012

Sacher, J., Neumann, J., Okon-Singer, H., Gotowiec, S., and Villringer, A. (2012) Sexual dimorphism in the human brain: evidence from neuroimaging. Magn. Reson. Imaging 31, 366-375. doi: 10.1016/j.mri.2012.06.007

Sacher, J., Okon-Singer, H., and Villringer, A. (2013). Evidence from neuroimaging for the role of the menstrual cycle in the interplay of emotion and cognition. Front. Hum. Neurosci. 7:374. doi: 10.3389/fnhum.2013.00374

Sandi, C. (2013). Stress and cognition. Wiley Interdiscip. Rev. Cogn. Sci. 4, 245-261. doi: $10.1002 /$ wcs. 1222

Schick, A., Wessa, M., Vollmayr, B., Kuehner, C., and Kanske, P. (2013). Indirect assessment of an interpretation bias in humans: neurophysiological and behavioral correlates. Front. Hum. Neurosci. 7:272. doi: 10.3389/fnhum.2013.00272

Schmitter, A. M. (2014). "17th and 18th century theories of emotions," in Stanford Encyclopedia of Philosophy, ed. E. N. Zalta (Stanford, CA: Stanford University). Available at: http://plato.stanford.edu/entries/emotions-17th18th/
Schouppe, N., De Houwer, J., Ridderinkhof, K. R., and Notebaert, W. (2012). Conflict: run! Reduced Stroop interference with avoidance responses. Q. J. Exp. Psychol. (Hove) 65, 1052-1058. doi: 10.1080/17470218.2012.685080

Schuyler, B. S., Kral, T. R., Jacquart, J., Burghy, C. A., Weng, H. Y., Perlman, D. M., et al. (2014). Temporal dynamics of emotional responding: amygdala recovery predicts emotional traits. Soc. Cogn. Affect. Neurosci. 9, 176-181. doi: $10.1093 / \mathrm{scan} / \mathrm{nss} 131$

Schwabe, L., and Wolf, O. T. (2013). Stress and multiple memory systems: from 'thinking'to 'doing. Trends Cogn. Sci. 17, 60-68. doi: 10.1016/j.tics.2012.12.001

Shackman, A. J., Fox, A. S., and Seminowicz, D. A. (in press). The cognitiveemotional brain: opportunities and challenges for understanding neuropsychiatric disorders. Behav. Brain Sci.

Shackman, A. J., Maxwell, J. S., Mcmenamin, B. W., Greischar, L. L., and Davidson, R. J. (2011a). Stress potentiates early and attenuates late stages of visual processing. J. Neurosci. 31, 1156-1161. doi: 10.1523/JNEUROSCI.3384-10.2011

Shackman, A. J., Salomons, T. V., Slagter, H. A., Fox, A. S., Winter, J. J., and Davidson, R. J. (2011b). The integration of negative affect, pain, and cognitive control in the cingulate cortex. Nat. Rev. Neurosci. 12, 154-167. doi: 10.1038/ nrn2994

Shackman, A. J., Mcmenamin, B. W., Maxwell, J. S., Greischar, L. L., and Davidson, R. J. (2009). Right dorsolateral prefrontal cortical activity and behavioral inhibition. Psychol. Sci. 20, 1500-1506. doi: 10.1111/j.1467-9280.2009. 02476.x

Shackman, A. J., Sarinopoulos, I., Maxwell, J. S., Pizzagalli, D. A., Lavric, A., and Davidson, R. J. (2006). Anxiety selectively disrupts visuospatial working memory. Emotion 6, 40-61. doi: 10.1037/1528-3542.6.1.40

Shansky, R. M., and Lipps, J. (2013). Stress-induced cognitive dysfunction: hormone-neurotransmitter interactions in the prefrontal cortex. Front. Hum. Neurosci. 7:123. doi: 10.3389/fnhum.2013.00123

Shechner, T., Britton, J. C., Perez-Edgar, K., Bar-Haim, Y., Ernst, M., Fox, N. A., et al. (2012). Attention biases, anxiety, and development: toward or away from threats or rewards? Depress Anxiety 29, 282-294. doi: 10.1002/da.20914

Shenhav, A., Botvinick, M. M., and Cohen, J. D. (2013). The expected value of control: an integrative theory of anterior cingulate cortex function. Neuron 79, 217-240. doi: 10.1016/j.neuron.2013.07.007

Shenhav, A., and Buckner, R. L. (2014). Neural correlates of dueling affective reactions to win-win choices. Proc. Natl. Acad. Sci. U.S.A. 111, 10978-10983. doi: 10.1073/pnas.1405725111

Sheppes, G., and Levin, Z. (2013). Emotion regulation choice: selecting between cognitive regulation strategies to control emotion. Front. Hum. Neurosci. 7:179. doi: 10.3389/fnhum.2013.00179

Siman-Tov, T., Papo, D., Gadoth, N., Schonberg, T., Mendelsohn, A., Perry, D., et al. (2009). Mind your left: spatial bias in subcortical fear processing. J. Cogn. Neurosci. 21, 1782-1789. doi: 10.1162/jocn.2009.21120

Singer, N., Eapen, M., Grillon, C., Ungerleider, L. G., and Hendler, T. (2012). Through the eyes of anxiety: dissecting threat bias via emotional-binocular rivalry. Emotion 12, 960. doi: 10.1037/a0027070

Southwick, S. M., Vythilingam, M., and Charney, D. S. (2005). The psychobiology of depression and resilience to stress: implications for prevention and treatment. Annu. Rev. Clin. Psychol. 1, 255-291. doi: 10.1146/annurev.clinpsy.1.102803.143948

Sreenivasan, K. K., Curtis, C. E., and D'esposito, M. (2014). Revisiting the role of persistent neural activity during working memory. Trends Cogn. Sci. 18, 82-89. doi: 10.1016/j.tics.2013.12.001

Stollstorff, M., Munakata, Y., Jensen, A. P., Guild, R. M., Smolker, H. R., Devaney, J. M., et al. (2013). Individual differences in emotion-cognition interactions: emotional valence interacts with serotonin transporter genotype to influence brain systems involved in emotional reactivity and cognitive control. Front. Hum. Neurosci. 7:327. doi: 10.3389/fnhum.2013.00327

Stout, D. M., Shackman, A. J., Johnson, J. S., and Larson, C. L. (2014). Worry is associated with impaired gating of threat from working memory. Emotion. doi: 10.1037/emo0000015 [Epub ahead of print].

Stout, D. M., Shackman, A. J., and Larson, C. L. (2013). Failure to filter: anxious individuals show inefficient gating of threat from working memory. Front. Hum. Neurosci. 7:58. doi: 10.3389/fnhum.2013.00058

Suls, J., and Martin, R. (2005). The daily life of the garden-variety neurotic: reactivity, stressor exposure, mood spillover, and maladaptive coping. J. Pers. 73, 1485-1510. doi: 10.1111/j.1467-6494.2005.00356.x 
Susskind, J. M., Lee, D. H., Cusi, A., Feiman, R., Grabski, W., and Anderson, A. K. (2008). Expressing fear enhances sensory acquisition. Nat. Neurosci. 11, 843-850. doi: $10.1038 / \mathrm{nn} .2138$

Todd, R. M., and Anderson, A. K. (2013). Salience, State, and expression: the influence of specific aspects of emotion on attention and perception. Oxford Handbook Cogn. Neurosci. 2, 11.

Todd, R. M., Cunningham, W. A., Anderson, A. K., and Thompson, E. (2012). Affect-biased attention as emotion regulation. Trends Cogn. Sci. 16, 365-372. doi: 10.1016/j.tics.2012.06.003

Treadway, M. T., Buckholtz, J. W., Martin, J. W., Jan, K., Asplund, C. L., Ginther, M. R., et al. (2014). Corticolimbic gating of emotion-driven punishment. Nat. Neurosci. 17, 1270-1275. doi: 10.1038/nn.3781

Uddin, L. Q., Kinnison, J., Pessoa, L., and Anderson, M. L. (2014). Beyond the tripartite cognition-emotion-interoception model of the human insular cortex. J. Cogn. Neurosci. 26, 16-27. doi: 10.1162/jocn-a-00462

Uhlhaas, P. J., and Singer, W. (2012). Neuronal dynamics and neuropsychiatric disorders: toward a translational paradigm for dysfunctional large-scale networks. Neuron 75, 963-980. doi: 10.1016/j.neuron.2012.09.004

Urry, H. L. (2010). Seeing, thinking, and feeling: emotion-regulating effects of gaze-directed cognitive reappraisal. Emotion 10, 125-135. doi: 10.1037/ a0017434

Vaisvaser, S., Lin, T., Admon, R., Podlipsky, I., Greenman, Y., Stern, N., et al. (2013). Neural traces of stress: cortisol related sustained enhancement of amygdala-hippocampal functional connectivity. Front. Hum. Neurosci. 7:313. doi: 10.3389/fnhum.2013.00313

van Ast, V., Spicer, J., Smith, E., Schmer-Galunder, S., Liberzon, I., Abelson, J., et al. (2014). Brain mechanisms of social threat effects on working memory. Cereb. Cortex doi: 10.1093/cercor/bhu206 [Epub ahead of print].

Van Bockstaele, B., Verschuere, B., Tibboel, H., De Houwer, J., Crombez, G., and Koster, E. H. (2013). A review of current evidence for the causal impact of attentional bias on fear and anxiety. Psychol. Bull. 140, 682-721. doi: $10.1037 / \mathrm{a} 0034834$

Van Dessel, P., and Vogt, J. (2012). When does hearing laughter draw attention to happy faces? Task relevance determines the influence of a crossmodal affective context on emotional attention. Front. Hum. Neurosci. 6:294. doi: 10.3389/fnhum.2012.00294

van Reekum, C. M., Johnstone, T., Urry, H. L., Thurow, M. E., Schaefer, H. S., Alexander, A. L., et al. (2007). Gaze fixations predict brain activation during the voluntary regulation of picture-induced negative affect. Neuroimage 36, $1041-$ 1055. doi: 10.1016/j.neuroimage.2007.03.052

Vincent, J. L., Patel, G. H., Fox, M. D., Snyder, A. Z., Baker, J. T., Van Essen, D. C., et al. (2007). Intrinsic functional architecture in the anaesthetized monkey brain. Nature 447, 83-86. doi: 10.1038/nature05758

Vogel, E. K., and Machizawa, M. G. (2004). Neural activity predicts individual differences in visual working memory capacity. Nature 428, 748-751. doi: 10.1038 /nature 02447

Vogel, E. K., Mccollough, A. W., and Machizawa, M. G. (2005). Neural measures reveal individual differences in controlling access to working memory. Nature 438, 500-503. doi: 10.1038/nature04171

Vytal, K. E., Cornwell, B. R., Letkiewicz, A. M., Arkin, N. E., and Grillon, C. (2013). The complex interaction between anxiety and cognition: insight from spatial and verbal working memory. Front. Hum. Neurosci. 7:93. doi: 10.3389/fnhum.2013.00093
Wager, T. D., Atlas, L. Y., Lindquist, M. A., Roy, M., Woo, C. W., and Kross, E. (2013). An fMRI-based neurologic signature of physical pain. N. Engl. J. Med. 368, 1388-1397. doi: 10.1056/NEJMoa1204471

Wald, I., Degnan, K. A., Gorodetsky, E., Charney, D. S., Fox, N. A., Fruchter, E., et al. (2013). Attention to threats and combat-related posttraumatic stress symptoms: prospective associations and moderation by the serotonin transporter gene. JAMA Psychiatry 70, 401-408. doi: 10.1001/2013.jamapsychiatry.188

Warren, S. L., Crocker, L. D., Spielberg, J. M., Engels, A. S., Banich, M. T., Sutton, B. P., et al. (2013). Cortical organization of inhibition-related functions and modulation by psychopathology. Front. Hum. Neurosci. 7:271. doi: 10.3389/fnhum.2013.00271

Watson, D., and Clark, L. A. (1984). Negative affectivity: the disposition to experience aversive emotional states. Psychol. Bull. 96, 465. doi: 10.1037/00332909.96.3.465

Webb, T. L., Miles, E., and Sheeran, P. (2012). Dealing with feeling: a meta-analysis of the effectiveness of strategies derived from the process model of emotion regulation. Psychol. Bull. 138, 775-808. doi: 10.1037/a00 27600

Whiteford, H. A., Degenhardt, L., Rehm, J., Baxter, A. J., Ferrari, A. J., Erskine, H. E., et al. (2013). Global burden of disease attributable to mental and substance use disorders: findings from the Global Burden of Disease Study 2010. Lancet 382, 1575-1586. doi: 10.1016/S0140-6736(13)61611-6

Wilson, S. J., Smyth, J. M., and Maclean, R. R. (2014). Integrating ecological momentary assessment and functional brain imaging methods: new avenues for studying and treating tobacco dependence. Nicotine Tob. Res. 16(Suppl. 2), S102-S110. doi: $10.1093 / \mathrm{ntr} / \mathrm{ntt} 129$

Woo, C. W., Koban, L., Kross, E., Lindquist, M. A., Banich, M. T., Ruzic, L., et al. (2014). Separate neural representations for physical pain and social rejection. Nat. Commun. 5, 5380. doi: 10.1038/ncomms6380

Xing, C., and Isaacowitz, D. M. (2006). Aiming at happiness: how motivation affects attention to and memory for emotional images. Motiv. Emot. 30, 243-250. doi: 10.1007/s11031-006-9032-y

Zaretsky, M., Mendelsohn, A., Mintz, M., and Hendler, T. (2010). In the eye of the beholder: internally driven uncertainty of danger recruits the amygdala and dorsomedial prefrontal cortex. J. Cogn. Neurosci. 22, 2263-2275. doi: 10.1162/jocn.2009.21402

Conflict of Interest Statement: The authors declare that the research was conducted in the absence of any commercial or financial relationships that could be construed as a potential conflict of interest.

Received: 14 November 2014; accepted: 21 January 2015; published online: 17 February 2015.

Citation: Okon-Singer H, Hendler T, Pessoa L and Shackman AJ (2015) The neurobiology of emotion-cognition interactions: fundamental questions and strategies for future research. Front. Hum. Neurosci. 9:58. doi: 10.3389/fnhum.2015.00058

This article was submitted to the journal Frontiers in Human Neuroscience.

Copyright (c) 2015 Okon-Singer, Hendler, Pessoa and Shackman. This is an openaccess article distributed under the terms of the Creative Commons Attribution License (CC BY). The use, distribution or reproduction in other forums is permitted, provided the original author(s) or licensor are credited and that the original publication in this journal is cited, in accordance with accepted academic practice. No use, distribution or reproduction is permitted which does not comply with these terms. 